Portland State University

PDXScholar

1989

\title{
In situ measurements of two amplified and one acoustic stethoscope
}

Sara Ruth Ann Oliver

Portland State University

Follow this and additional works at: https://pdxscholar.library.pdx.edu/open_access_etds

Part of the Speech and Hearing Science Commons Let us know how access to this document benefits you.

\section{Recommended Citation}

Oliver, Sara Ruth Ann, "In situ measurements of two amplified and one acoustic stethoscope" (1989). Dissertations and Theses. Paper 3932.

https://doi.org/10.15760/etd.5816

This Thesis is brought to you for free and open access. It has been accepted for inclusion in Dissertations and Theses by an authorized administrator of PDXScholar. Please contact us if we can make this document more accessible: pdxscholar@pdx.edu. 
AN ABSTRACT OF THE THESIS OF Sara Ruth Ann Oliver for the Master of Science in Speech Communication presented February 10, 1989.

Title: In Situ Measurements of Two Amplified and One Acoustic stethoscope.

APPROVED BY THE MEMBERS OF THE THESIS COMMITTEE:

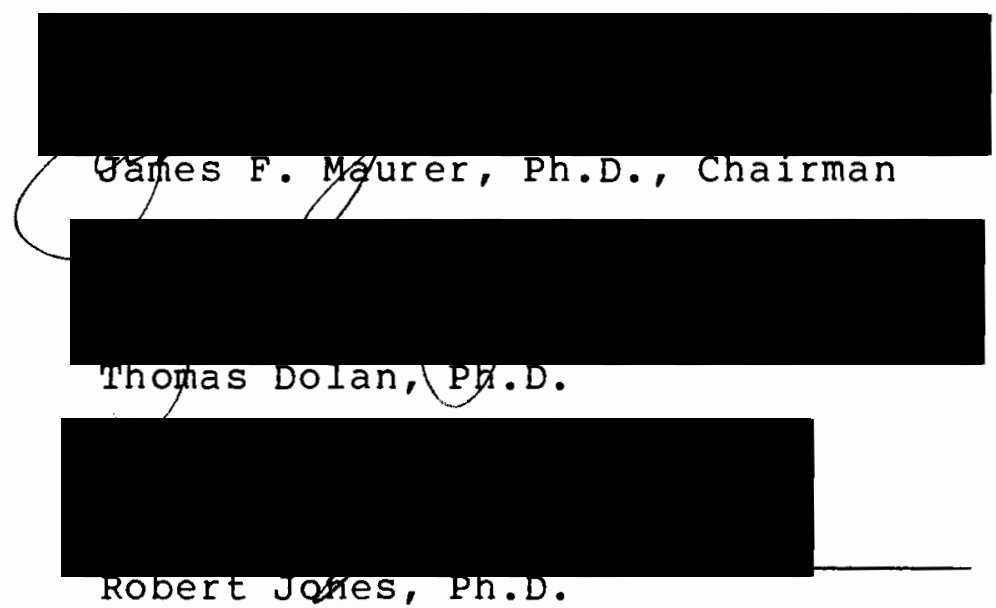

This study investigated the following questions: 1) What is the spectra of human heart sounds when transmitted to the listener's ear through amplified and acoustic stethoscopes? 2) How does the acoustic spectrum of normal heart sounds compare to the threshold of audibility for normal hearing sensitivity? 3) Do normal hearing listeners elect to listen to heart sounds at a higher intensity than the acoustic stethoscope is able to 
transmit?

Eleven normal hearing adults (six females and five males) served as listening subjects for evaluating the stethoscopes with normal heart sounds from a young adult male model as the input signal.

A probe microphone was situated at the entrance of each subject's ear canal, and the output transmitted by each stethoscope was measured by a Rockland Fast Fourier Transform Analyzer. The output of normal heart sounds, transmitted by the amplified stethoscopes, was measured at a level selected as most comfortable, while maximum output was measured for the acoustic stethoscope.

Comparison of the mean outputs of the three stethoscopes suggested that the level that was most comfortable for auscultation of normal heart sounds was greater than the maximum output of the acoustic stethoscope. Since the acoustic stethoscope is the most universally employed in medical settings, this investigation raises questions about its psychoacoustic efficacy for monitoring human heart sounds when compared to amplified stethoscopes. 


\title{
IN SITU MEASUREMENTS OF TWO AMPLIFIED
}

AND ONE ACOUSTIC STETHOSCOPE

by

SARA RUTH ANN OLIVER

A thesis submitted in partial fulfillment of the requirements for the degree of

\author{
MASTER OF SCIENCE \\ in \\ SPEECH COMMUNICATION \\ with emphasis in Speech Pathology \\ and Audiology
}

Portland State University 
TO THE OFFICE OF GRADUATE STUDIES:

The members of the committee approve the thesis of Sara Ruth Ann Oliver presented February 10, 1989.

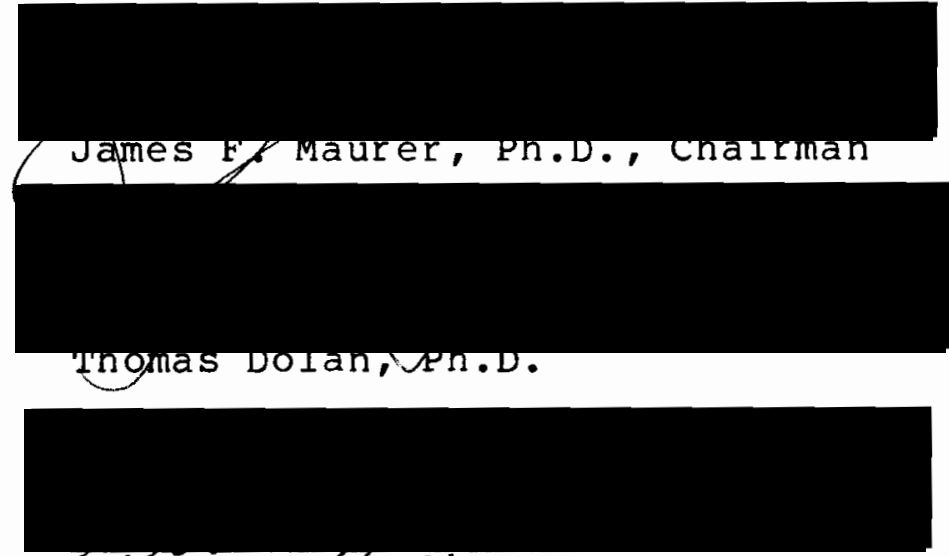

Robert Jones, Ph.D.

APPROVED:

Theodore G. Grove, chair, Department of speech Communication

Bernard Ross, Vice provost for Graduate studies 


\section{ACKNOWLEDGEMENTS}

Upon completion of this thesis it is only fitting that I take this small moment of time to extend my deepest gratitude to each individual who helped me in the process of completing this project. Thank you to my brother David and each volunteer for your patience, participation and mostly for your interest in learning. Thank you Pat and Elizabeth for putting up with my lack of participation in the daily routines, and your unending moral support. A hardy thank you to my thesis committee members James Maurer, Thomas Dolan and Robert Jones for your time, your teaching and your friendship. Without each one of you I wouldn't have accomplished by goal. Thank you. 
TABLE OF CONTENTS

PAGE

ACKNOWLEDGEMENTS $\ldots \ldots \ldots \ldots \ldots \ldots \ldots \ldots \ldots \ldots$ i $\ldots \ldots \ldots \ldots \ldots$

LIST OF FIGURES $\ldots \ldots \ldots \ldots \ldots \ldots \ldots \ldots \ldots \ldots \ldots$ vi

CHAPTER

I INTRODUCTION $\ldots \ldots \ldots \ldots \ldots \ldots \ldots \ldots \ldots \ldots$

I I REVIEW OF THE LITERATURE $\ldots \ldots \ldots \ldots \ldots \ldots \ldots \ldots$

Acoustic stethoscope ................ 9

Frequency response

Intensity range

Amplified Stethoscope .............. 14

Heart sounds $\ldots \ldots \ldots \ldots \ldots \ldots \ldots \ldots \ldots \ldots$

The Human Hearing and Stethoscopes ....... 16

In situ Measurements $\ldots \ldots \ldots \ldots \ldots \ldots \ldots$

Statement of the Problem ............ 18

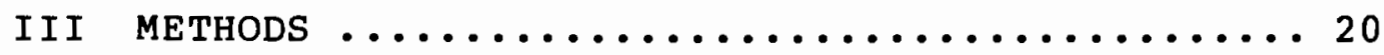

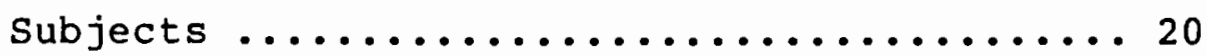

Equipment $\ldots \ldots \ldots \ldots \ldots \ldots \ldots \ldots \ldots \ldots \ldots \ldots \ldots \ldots \ldots$

Procedures ...................... 21

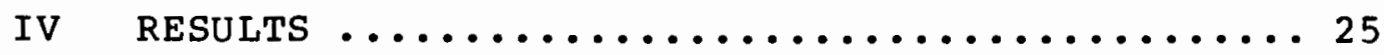

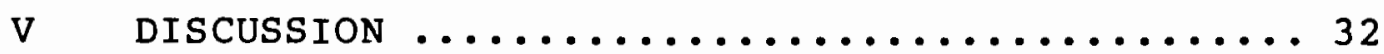

vi $\quad$ SUMMARY $\ldots \ldots \ldots \ldots \ldots \ldots \ldots \ldots \ldots \ldots \ldots \ldots \ldots \ldots \ldots$ 
AP PENDIX

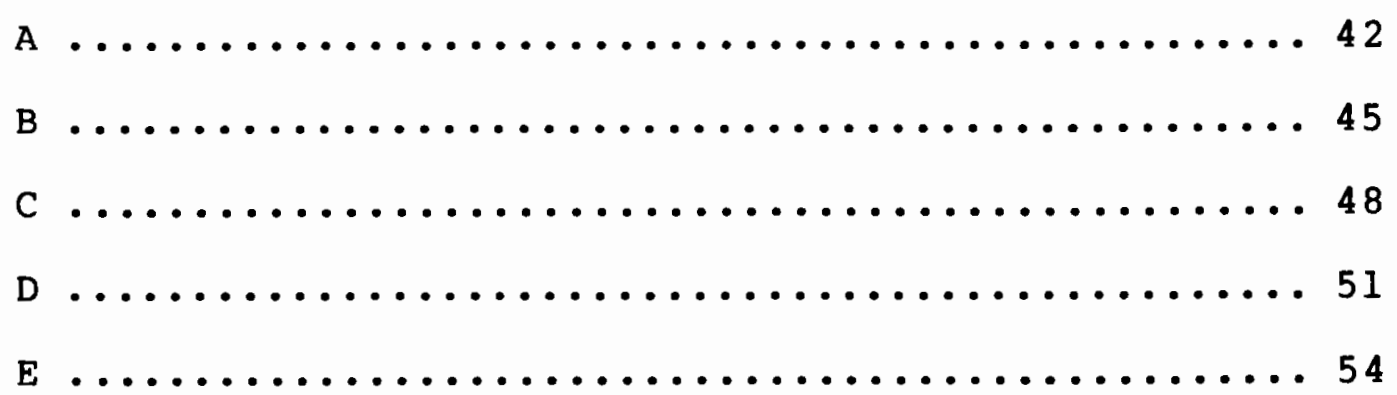




\section{LIST OF FIGURES}

\section{FIGURE}

1. Threshold of audibility ................ 4

2. Block diagram of the equipment used ........ 21

3. A Picture of the stethoscopes used for this

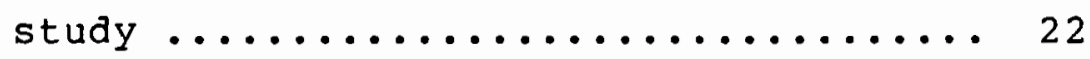

4. Raw data of amplified stethoscope B at

selected MCL for subject VII ........ 26

5. Raw data of amplified stethoscope $C$ at

selected MCL for subject VII ........ 27

6. Raw data of acoustic stethoscope A for

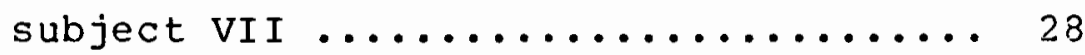

7. Mean output of three stethoscopes in dB

SPL as a function of frequency ...... 30 


\section{CHAPTER I}

\section{INTRODUCTION}

The acoustic stethoscope has been used to listen to sounds that originate within body organs as a means of diagnosis since its invention in 1916. The use of this device formed an early foundation for clinical knowledge regarding heart disease (Groom, 1964; Sakula, 1981). Today it continues to be widely used in the medical profession as a means of making preliminary diagnosis (Littmann, 1972).

Because the stethoscope is relied upon so heavily, researchers have studied many facets of its design. The chestpiece, bell and diaphragm, (Fredrick \& Dodge, 1924; Groom, 1964; Johnston \& Kline, 1940; Littmann, 1972; Rappaport \& Sprague, 1941), and earpieces of the acoustic stethoscope (Groom \& Chapman,'1959; Rappaport \& Sprague, 1952) have all been investigated.

The main function of the stethoscope is to bring physiological sounds to the listener's ears. To be of any use these sounds must reach the ear at a level above the listeners threshold of audibility and within the frequency range of the 1 istener. 
Different organs within the human body produce sounds of different intensity and frequency. This study will focus only on the sounds produced by normal heart function. The frequency $r$ ange of normal heart sounds has been reported to be in the vicinity of 10 to $1000 \mathrm{~Hz}$ (Rappaport \& Sprague, 1941; Williams \& Dodge, 1926). Also the acoustic stethoscope transmits frequencies below 1000 $\mathrm{Hz}$.

Studies of the frequency response of acoustic stethoscopes using pure tones as the input signal, have demonstrated a myriad of response curves, with energy peaks at frequencies ranging from 125 to $800 \mathrm{~Hz}$ (Ertel, Lawrence, Brown \& Stern, 1966a; Johnston \& Kline, 1940; Kindig, Beeson, Campbell, Andries \& Tavel, 1982; Rappaport \& Sprague, 1951, 1952). A review of the literature failed to reveal the frequency response of the acoustic stethoscope using monitor normal heart sounds as the input signal.

Consistent with the capabilities of the acoustic stethoscopes ability to transmit frequencies below 1000 $\mathrm{Hz}$, the listener must be able to hear frequencies below $1000 \mathrm{~Hz}$. Von Bekesy (1960) demonstrated that the lowest frequency perceived by humans is approximately $20 \mathrm{~Hz}$. He pointed out that as the frequency decreases the sound pressure required to perceive the tone increases. The 
threshold of audibility for frequencies of 125-4000 $\mathrm{Hz}$ (ANSI, 1969) is shown in Figure 1.

Taking into account how the human ear perceives sound, the stethoscope will need to transmit the low frequency heart sounds to the listener's ear at a rather high sound pressure level (e.g. $45 \mathrm{~dB}$ SPL at $125 \mathrm{~Hz}$ ). Since heartbeat sounds characteristically are low in frequency and sound pressure level, the question then arises whether the ear is sensitive enough to perceive heartbeats. A review of the literature did not adequately answer this question.

Energy peaks of heart sounds reportedly reach the eartips of the acoustic stethoscope at a very low level near the threshold of audibility for normal hearing individuals (Groom, 1956, 1964; Williams \& Dodge, 1926), although the method by which this was determined in these studies was not indicated. Kindig, et al. (1982) reported no significant amplification of taped heart sounds by the acoustic stethoscopes tested. According to Groom (1956), the intensity level required by different physicians to hear heart murmurs and heart sounds in quiet and in noisy environments varies with each physician. Furthermore, all individuals listening to heart sounds through the acoustic stethoscope do not have normal hearing. If a listener has poorer than normal thresholds or if he is listening in 


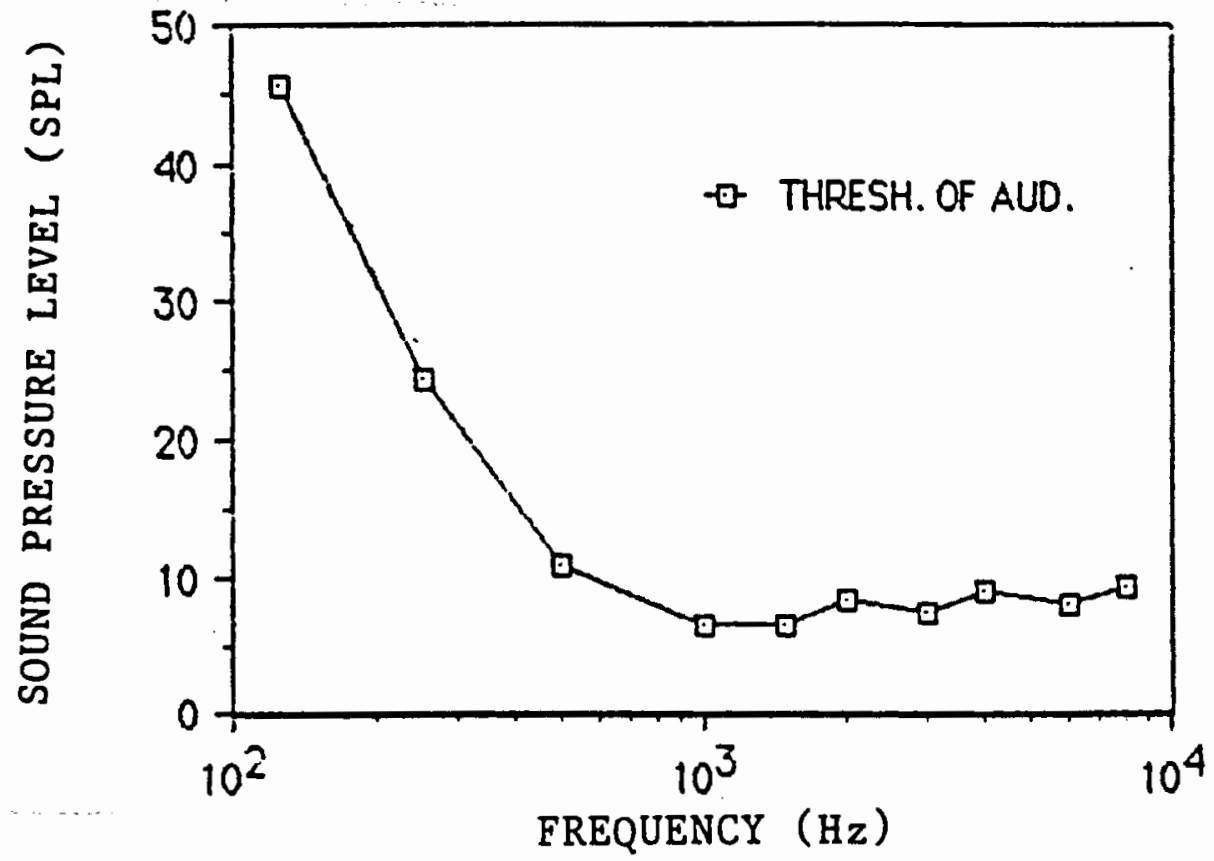

Figure 1. Threshold of audibility. Standard reference threshold sound pressure levels decibels relative to 0.0002 microbar (ANSI, 1969). 
background noise, he may not hear the intended sounds. Preliminary diagnosis of heart pathologies may be difficult in this case. It would be beneficial to present the heart sounds to the 1 isteners ears at a level that they choose as most comfortable.

The ability to hear through any stethoscope is greatly reduced in background noise (Groom, 1956, 1964; Kindig, et al., 1982). The acoustic stethoscope provides no means of adjustment to accommodate for the different levels required by different 1 isteners in a variety of noisy environments. However, amplified or electronic stethoscopes have the means of increasing the body signal at the listeners ears. These instruments are equipped with a power supply, amplifier, and volume control. The volume control allows the listener to adjust the body signal to a level that is comfortably audible.

Unfortunately, comprehensive acoustic data on these devices have not been published. For example, the manufacturer's specifications for the starkey ST 3 amplified stethoscope include the frequency response characteristics of it's amplifier, but the company does not report the frequency response of the entire unit. Equally vague are the specifications on the Bosch EST 40 electronic stethoscope.

The advent in the late 1980's of refined instrumentation for measuring and recording sound in the 
ear canal of the listener provides a new technology for investigating stethoscope output. Real-ear or in situ measurements have not been used to study these devices, except by Ertel, et al. (1966a), who determined pure tone threshold levels of listeners wearing an acoustic stethoscope. However, this investigation did not assess the spectral characteristics of the stethoscope output for thoracic sounds, such as heartbeats.

The evaluation of the output of stethoscopes under real ear conditions must take into account the resonating characteristics of the ear canal (Gilman, Dirks, \& Stern, 1981). When the ear is occluded by stethoscope eartips, the situation is similar to that of an in-the-ear (ITE) hearing aid or an earmold. Studies involving these devices have shown that there is little or no enhancement of frequencies below $1.5 \mathrm{k} \mathrm{Hz}$ associated with ear canal occlusion (Gilman \& Dirks, 1984; Gilman, Dirks \& Stern, 1981; Zemplenyi, Dirks \& Gilman, 1985). Since the heartbeat signal is well below the frequency range that is enhanced by occluding the ear, we would not expect the heart sounds in the ear canal to be enhanced by ear canal resonance. However, this expectation has not been investigated by means of real ear (in situ) measurements. This study aimed to clarify the relationship between the human heart sounds and listener perception of this event, 
as derived from real ear measurements of acoustic and amplified stethoscopes.

In adition, this study sought to determine if the selected output of the amplified stethoscope is greater than the output of the acoustic stethoscope by measuring the spectra of normal heart sounds in the human ear canal of listeners by means of a probe microphone and real-time spectrum analyzer. 


\section{CHAPTER I I}

\section{REVIEW OF THE LITERATURE}

In 1816 when R.T.H. Laennec rolled a quire of paper, placed one end of it to a patient's chest and the other to his ear, he probably didn't realize the impact of this simple acoustic principle. His improved ability to hear the sounds from the thoracic cavity urged him to develop an instrument constructed of wood. He called the instrument a stethoscope, arriving at the word from the Greek words meaning chest and to inspect. It was with this stethoscope that he studied and recorded auscultatory information. He later wrote a masterpiece titled De l'Auscultation Mediate, from which much of our present knowledge of heart sounds extends (Rappaport \& Sprague, 1941; Sakula, 1981).

There have been many modifications of Laennec's stethoscope. Piorry in 1828 added an earpiece and trumpet-shaped chestpiece known as the bell. The binaural stethoscope which used lead tubing, was first introduced in 1843 by C.J.B. Williams. Some years later, in 1855, George P. Cammann added flexible tubing (Rappaport \& Sprague, 1941). 


\section{ACOUSTIC STETHOSCOPE}

Many modifications transpired before the stethoscope was refined into the instrument commonly used in diagnostic examinations today. The main function of the modern stethoscope is to deliver the sounds generated within the body to the ear of the listener in a manner that enables auscultation (Rappaport \& Sprague, 1941).

Leakage of the sounds at any point from chestpiece to earpiece will result in a decrease in the efficiency in which the sound is being delivered to the ears (Kindig, et al. 1982). A common point of leakage is where the eartips enter the ear canal (Groom, 1959; Rappaport \& Sprague, 1952). Enhancement of a seal at this point can be made if the eartubes of the stethoscope are positioned anteriorly. This follows the normal direction of the ear canal and may help to prevent leakage (Groom, 1959; Littmann, 1972). The size of the eartip is also a matter of concern. A small eartip may be partially or completely occluded by the anterior part of the ear canal resulting in a reduction of sound transmission. The most desirable eartips would be the largest possible that will still fit easily into the ear canal (Groom, 1959).

Sound transmission through the stethoscope is affected by its tubing as well. Although the binaural stethoscope is more commonly used, a single tube, or 
monaural stethoscope, is available.

Support for a binaural, rather than a monaural stethoscope was discovered when it was determined that the former produced a $20 \mathrm{~dB}$ SPL improvement for frequencies 60 to $400 \mathrm{~Hz}$ when compared to the monaural stethoscope (Rappaport and Sprague, 1941). This corresponds to a tenfold increase in sound pressure being presented to the ear. The monaural tubing performed superior to the binaural through the range of 850 to $1000 \mathrm{~Hz}$ by approximately 5 dB (Rappaport \& Sprague, 1941).

However, Kindig, et al. (1982) examined identical stethoscope models with one being single tube and the other double tubing. They found very little difference in output existed between them up to $400 \mathrm{~Hz}$, at which point the single tube began to perform less efficiently. In terms of $l$ istener preferences no significant difference was found, quantitatively or qualitatively, between the two stethoscopes when subjects listened to taped heart sounds.

The binaural stethoscope was reported to have the disadvantage of being bulky and presenting distracting noises from the tubes rubbing together (Littmann, 1972). Yet, as Groom noted in an earlier report, it allows for occlusion of both ears, preventing room noises from entering either ear a phenomena that does occur monaural 
stethoscopes (Groom, 1956).

It should emphasized that many of the benefits and disadvantages reported on both types of stethoscopes were somewhat subjective and anecdotal, arising from clinical experience rather than from acoustic or physiological measures.

Even the length of tubing that provides the most efficient sound transmission remains surrounded by controversy. According to Rappaport and sprague (1941), the efficiency of the stethoscope is not affected by its tubing length for frequencies below $100 \mathrm{~Hz}$, although above $100 \mathrm{~Hz}$, the efficiency decreases as the tubing length increases for frequencies up to $1000 \mathrm{~Hz}$. Twenty inches from chestpiece to eartips was found to be efficient and practical by Groom (1964). Others suggested a stethoscope should be long enough to reach over bedrails or about 20 inches from yoke to chestpiece. Littmann (1972) suggested a significant difference in performance occurs as a function of tubing length only when comparing 6 inch tubing to 36 inch tubing. It is generally agreed that the shorter the tubing, the more efficient the sound transmission (Groom, 1964; Littmann, 1972; Rappaport \& Sprague, 1941). A more conservative measurement of tubing length would then be 20 inches from chestpiece to eartips, as recommended earlier by Littmann (1972).

Another structural aspect of the stethoscope that 
affects sound transmission is the chestpiece. There are two basic types, the bell and diaphragm. The bell, or sometimes called the "Ford" chestpiece, has the ability to transmit sounds with minimal subjective change in quality or pitch (Littmann, 1972). The diameter of the bell is usually not larger than one inch. According to Littmann (1972) this device is effective in "the perception of certain low-pitched sounds, such as the diastolic murmurs of mitral stenosis and for some gallop sounds".

The diaphragm chestpiece is commonly used for screening, blood pressure cuff measurements and general routine evaluations. The chestpiece filters out low frequencies and, as a result, transmits sounds that are higher in pitch than for the bell (Littmann, 1972). Rappaport \& Sprague (1941) reported that "high pitched, diastolic murmurs of aortic insufficiency" could be heard with its use.

An advantage of the diaphragm chestpiece is in its design. Since it is sealed by its own diaphragm, it eliminates the need for a complete seal with the skin. In addition, the larger size diameter allows more sound to be picked up then with the bell (Fredrick \& Dodge, 1924; Littmann, 1972).

Although, the bell chestpiece has been found to transmit taped heart sounds better than the diaphragm the 
Frequency Response

Pure tones have been used to evaluate the acoustical properties of the stethoscope since 1924 (Ertel, et al., 1966a, 1966b; Fredrick \& Dodge, 1924; Johnston \& Kline, 1940; Kindig, et al., 1982; Rappaport \& Sprague, 1951, 1952). Various results have demonstrated a myriad of fluctuating curves with peaks ranging from 125 to $800 \mathrm{~Hz}$. These results have been used as a measure of how the stethoscope may function in a clinical settings. Thoracic sounds, however, are complex sounds. Recognizing this, Groom (1956, 1964) and Kindig, et al., (1982) utilized taped heart sounds as the input signal. Their results revealed a slighty lower peak frequency range, specifically 75 to $125 \mathrm{~Hz}$.

\section{Intensity Range}

It has been reported that heart sounds reach the eartips of the acoustic stethoscope at a very low intensity, near the threshold of audibility for normal hearing individuals (Groom, 1956, 1964; Williams \& Dodge, 1926). With the heart sounds being delivered to the ear canal through the acoustic stethoscope near the threshold of audibility, background noise may interfere with auscultation. The difficulty of auscultation in noise has been reported throughout the literature (Groom, 1956, 1964; Kindig et al., 1982; Williams \& Dodge, 1926). Groom measured an average of $65 \mathrm{~dB}$ SPL background noise on 
the hospital wards he evaluated (Groom, 1956). He suggested the most effective means of improving the accuracy of cardiac auscultation is by means of reducing background noise (Groom, 1964), thus improving the signal to noise ratio. Another option would be to increase the signal level; that is, the level of the heart sounds. An amplified stethoscope equipped with a microphone, power supply, amplifier and volume control is capable of increasing the intensity of the signal thereby reducing the effects of the background noise.

\section{AMPLIFIED STETHOSCOPE}

Early studies show the development of the electrical stethoscope as a teaching instrument used in classrooms or lecture halls (Fredick \& Dodge, 1924; Gamble \& Repologle, 1924 ; Rappaport \& Sprague, 1941). General clinical realization that amplified stethoscopes facilitate auscultation has dawned slowly and little support for the concept is found in the scientific literature. Currently, this type of instrument is available through some hearing aid companies.

According to various manufacturers specifications, the basic amplified stethoscope can increase the intensity of the signal approximately 30 to $40 \mathrm{~dB}$ SPL. This intensity increase may greatly facilitate auscultation of heart sounds. Information on the capabilities of the 
amplified stethoscope to transduce sounds below $100 \mathrm{~Hz}$ however, is not discussed in the manufacturers literature.

\section{HEART SOUNDS}

Sounds associated with heart muscle contraction consist of two distinct wave forms. The first heart tone is the result of the action of the "auricular and ventricular" heart muscle, while the second tone results from the closure of the "semilunar valves" (Littmann, 1972; Richard, 1956; Williams \& Dodge, 1926).

The frequency $r$ ange of the heart sounds is dependent upon the abruptness of the valve closure. The more abrupt the closure, the more prominent the high frequency components. Abruptness varies with each individual and therefore the frequency (Richard, 1956; Williams \& Dodge, 1926). However, there is a range where most heart sounds important to auscultation are found. Generally, these frequencies are below $1000 \mathrm{~Hz}$ (Cabot\& Dodge, 1925). More specifically, for high pitched murmurs, the upper frequency limit is $660 \mathrm{~Hz}$ (Williams \& Dodge, 1926). No noticeable value for heart sounds is present above $650 \mathrm{~Hz}$ (Rappaport \& Sprague, 1941) and the greatest energy level is between 50 to $60 \mathrm{~Hz}$ (Williams \& Dodge, 1926). These authors found the lower frequency range of heart sounds to be in the vicinity of 5 to $10 \mathrm{~Hz}$; however, measurement methodologies vary in these early studies, and the results 
are somewhat questionable.

THE HUMAN HEARING AND STETHOSCOPES

Auscultation of heart sounds is performed by listening to sounds below $1000 \mathrm{~Hz}$ and making a judgement regarding the status of the heart. The ability to do this is based on the listeners training, experience, and hearing acuity, as well as the amount of ambient noise in the environment. Normal human hearing sensitivity is poorest at low frequencies. More energy is needed in low frequencies to be audible for normal hearing than for other frequencies (Fletcher \& Munson, 1933; Sivian \& White, 1933). This is significant because heart sounds are low frequency sounds. With most of the heart sounds Ealling below $1000 \mathrm{~Hz}$, the acoustic stethoscope optimally would need to transmit these sounds at relatively high levels in order for them to be just audible to the listener.

The eartips of a stethoscope present sounds directly into the ear canal and by doing so, actually bypass the parabolic resonating influences of the pinna. The ear canal and ear drum, however, continue to interact by increasing the sound pressure level at frequencies above $1500 \mathrm{~Hz}$ (Gilman \& Dirks, 1981, 1984; Hardford, 1980; Wiener \& Ross, 1946).

When the entrance of the ear canal is occluded by the 
eartips of the stethoscope and sound is being delivered at some point along the ear canal, the situation is similar to that of an earmold or in-the-ear (ITE) hearing aid. That is, the resonating frequencies of the ear canal when occluded by an eartip of a stethoscope would be essentially the same as when occluded by an earmold or ITE hearing aid. Research has shown the sound pressure level at the ear drum to be reasonably unaffected by ear canal resonance below $1500 \mathrm{~Hz}$ for air conducted sounds when the ear is occluded by a hearing aid or earmold (Gilman \& Dirks, 1981, 1984; McDonald \& Studebaker, 1970).

\section{IN SITU MEASUREMENTS}

Probe microphones have been used to measure ear canal sound pressure levels in many hearing aid and earmold investigations (Ewertsen, et al., 1957; Gilman \& Dirks, 1984; Harford, 1980; Shaw, 1966; Shaw \& Lawton, 1982; McDonald \& Studebaker, 1970; Zemplenyi, et al., 1985). The use of the probe tube measurement has been useful in revealing the actual intensity and frequency response that a hearing aid is delivering to the eardrum. The literature revealed only one study, by Ertel et al. $(1966 a)$, in which a probe microphone was used to evaluate stethoscope acoustics, unfortunatly the stethoscope tubing was modified to accommodate the probe microphone. The literature is in agreement on the lack of 
influence that the length of the occluded ear canal and the insertion depth of the probe tubes have on frequencies below $1000 \mathrm{~Hz}$ (Gilman \& Dirks, 1981, 1984; Harford, 1980; Zemplenyi, et., 1985). Given that heart sounds are below $1000 \mathrm{~Hz}$ an average midpoint placement of the probe tube is sufficient. This distance is reported to be $12 \mathrm{~mm}$ (Harford, 1980).

Listening to heart sounds through a stethoscope is clearly dependent on listeners hearing sensitivity. Little research has been done to evaluate this relationship. More emphasis seems to have been placed on the acoustic contributions of individual parts of the stethoscope than on the hearing threshold of the listener. The intensity level of sounds that are transmitted through the acoustic and the frequency response of amplified stethoscopes are not well defined.

Further research was needed to clarify the functional response characteristics of amplified stethoscopes and how their output is different from acoustic stethoscope output. In addition, more information was needed on the relationship between the stethoscope and its user.

\section{STATEMENT OF THE PROBLEM}

This study addressed the following questions: What is the frequency spectra of human heart sounds when transmitted through amplified and acoustic stethoscopes? 
2) How does the acoustic spectrum of normal heart sounds compare to the threshold of audibility for normal hearing sensitivity? 3) Do the listeners elect to listen to the heart sounds at a higher intensity than the acoustic stethoscope is able to transmit? 


\section{CHAPTER III}

\section{METHODS}

\section{SUBJECTS}

Eleven adult subjects, 6 females and 5 males, ranging from 20 to 40 years old were selected from a group of volunteers. All subjects demonstrated normal otoscopy, pure tone thresholds of $15 \mathrm{~dB} \mathrm{HL}$ (ANSI 1969) or lower at test frequencies of 125 through $8000 \mathrm{~Hz}$, and normal tympanometric peak pressures $(+-50$ daPa) bilaterally. In addition to these eleven subjects, a nurse with cardiac experience and hearing within normal limits (15 dB HL or lower at 125-8000 $\mathrm{Hz}$ ) was selected to act as a consultant on stethoscopic procedures for heart auscultation. Finally, a young adult male (age 29) was selected by the nurse following auscultation as a source for normal heart sounds. Previous medical examinations on this subject by a physician revealed normal heart auscultation.

\section{EQU I PMENT}

The heart sounds being analyzed were received by a Knowles microphone, amplified by an operational amplifier and fed into a Rockland 5840A Fast Fourier Transform 
Analyzer. A hard copy of the real-time analysis was obtained by a Graphic MP $2000 \mathrm{x}-\mathrm{y}$ plotter. A diagram of the equipment used can be seen in Figure 2 .

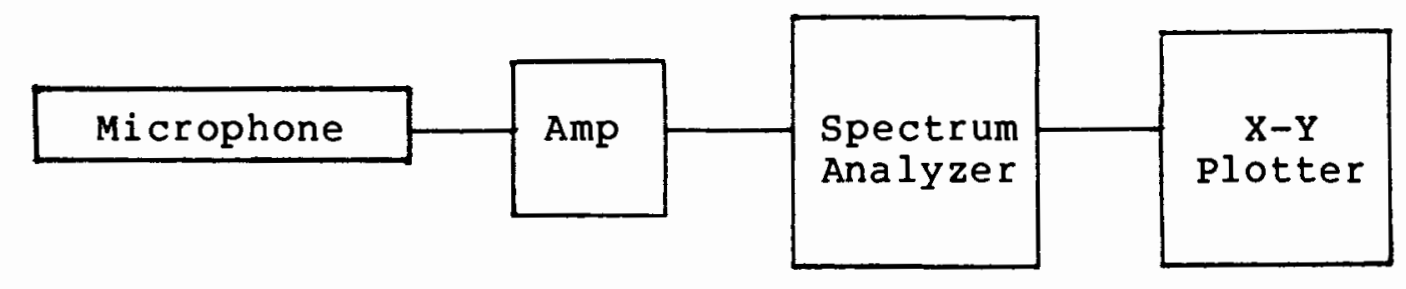

Figure 2. Block diagram of equipment used for this study.

\section{PROCEDURES}

The nurse was asked to identify the location on the model's exposed chest where heart sounds were most clearly audible. Using a Sprague-Rappaport LAB 600 acoustic stethoscope in an acoustic chamber, the nurse identified this point, and an "x" was marked on the model's chest at the designated location. This position was later used as the center point placement of the three stethoscope chestpieces used in this study. These stethoscopes can be seen in Figure 3 and are referred to as $A$ (acoustic, Sprague-Rappaport LAB 600), B (amplified, Bosch EST 40), and C (amplified, Starkey ST 3).

Each subject was seated next to the adult male model in a sound room. A probe tube was placed approximately 12 $\mathrm{mm}$ into each subject's right ear canal. This distance was found to be approximately midway between the entrance of 


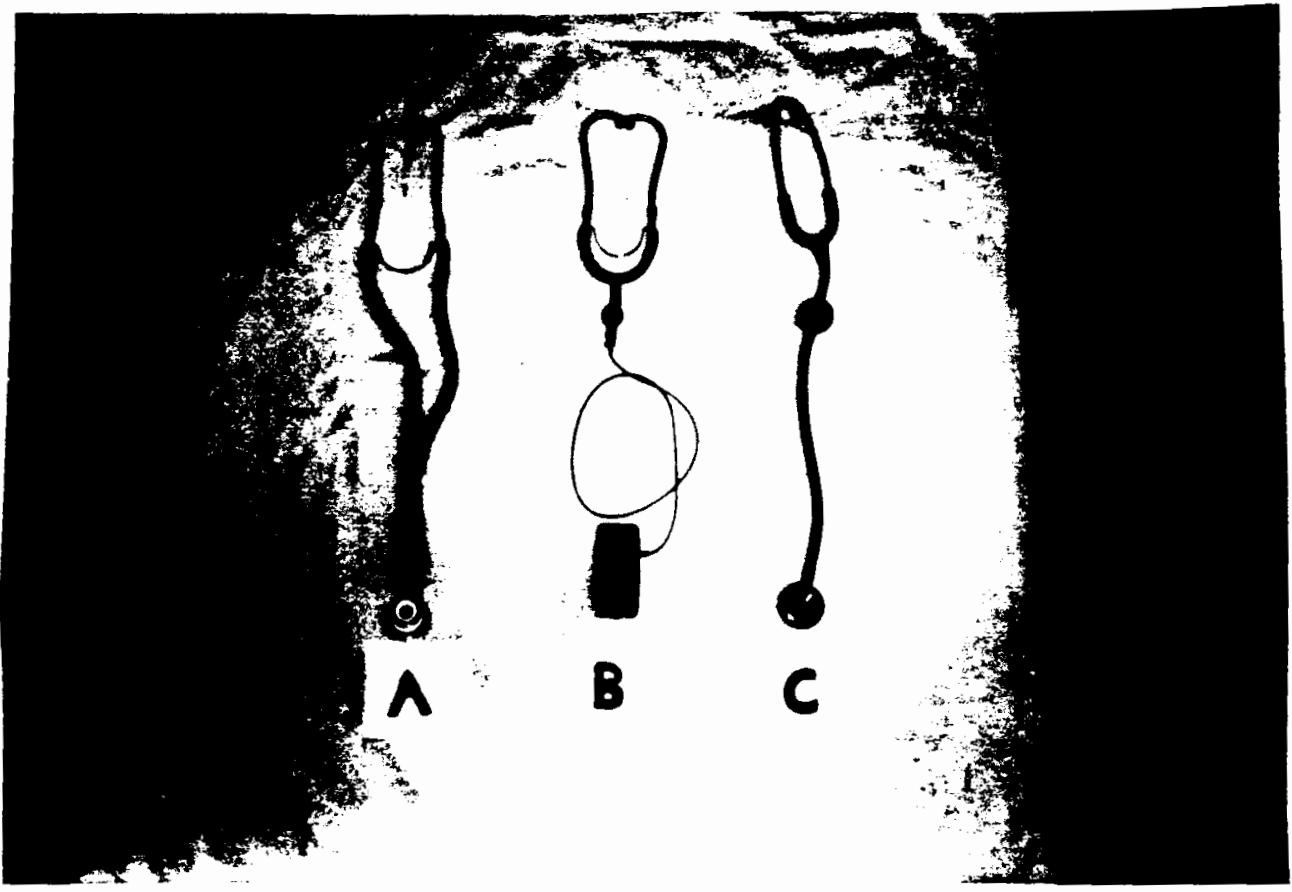

Figure 3. A picture of the stethoscopes used for this study. The Sprague-Rappaport LAB 600 acoustic stethoscope was designated as stethoscope $A$, the Bosch EST 40 amplified stethoscope as B and the starkey ST 3 amplified stethoscope as $C$. 
the canal and the eardrum, after Harford (1980). This placement was facilitated by aligning a mark on the probe tube with the entrance of the ear canal. The probe tube assembly wire was taped to the subject's face near the temporalmandibular joint, as well as to the left shoulder to prevent movement of the probe tube. The eartips of each stethoscope were then placed in the subject's ears in respective order by the experimenter. In each case the chestpiece of stethoscope was aligned and hand held on the model's chest at the designated mark, consistent with clinical procedure. Measurements were then made of the heart sounds being delivered by the stethoscope to the subject's ear.

Additional adjustment procedures were necessary for the two amplified stethoscopes because of their variable output. Each subject was instructed to adjust the volume control upward from its lowest setting to its highest setting, descending to a most comfortable listening level $(M C L)$. This ascending-descending procedure was repeated for a minimum of two trials or until the subject indicated that heart sounds were being received at a comfortable listening level. The Sound Pressure Levels of the amplified heart sounds were then measured through the probe system at each volume control setting associated with MCL. 
The order in which the three stethoscopes were assigned to subjects was randomized. In addition, three subjects were randomly chosen to repeat the procedures on all three stethoscopes for the purpose of obtaining a measure of test re-test reliability. 
CHAPTER IV

\section{RESULTS}

The most prominent result of this study is that listeners with hearing sensitivity within normal limits preferred to listen to normal human heart sounds at a greater intensity level than the acoustic stethoscope is capable of delivering. In addition, test re-test reliability was relatively high for the three stethoscopes used. Stethoscope A demonstrated the highest test re-test reliability with a correlation between SPLs at various frequencies of .99. Correlations for stethoscopes B and C were .97 and .91 , respectively.

The raw data for subject VII show the propensity of the output at the selected MCL for the amplified stethoscopes, B (Figure 4) and C (Figure 5), to be at a greater output then the output of the acoustic stethoscope A (Figure 6). In order to obtain the results for this study, the sound pressure level was taken from each subject's raw data of the acoustic and amplified stethoscopes and was averaged at $50 \mathrm{~Hz}$ intervals. The numbers representing the sound pressure levels and their averages can be seen in appendix B through $D$. In 


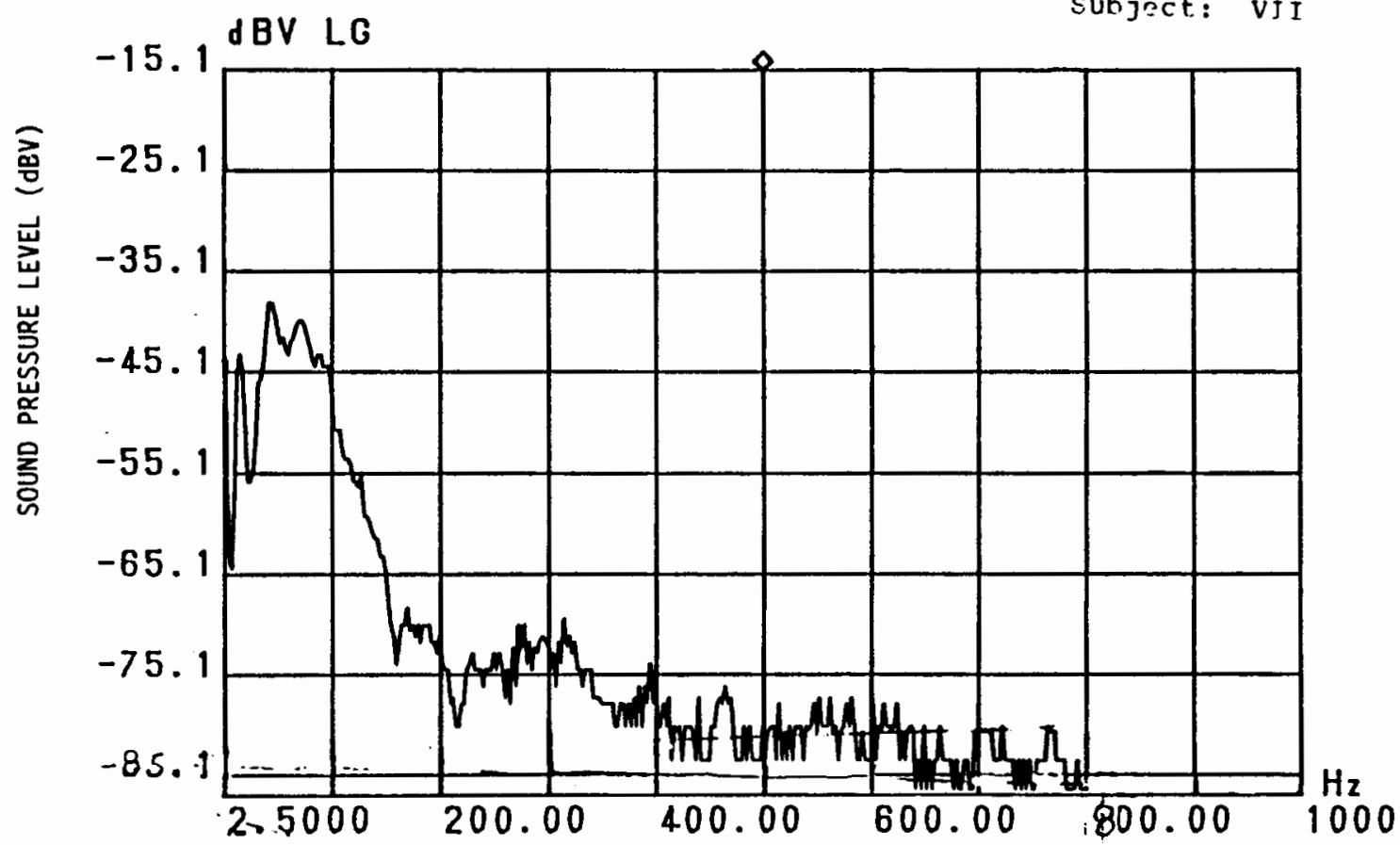

FREOUENCY $(\mathrm{Hz})$ Figure
MCI for for dubject VJI. 


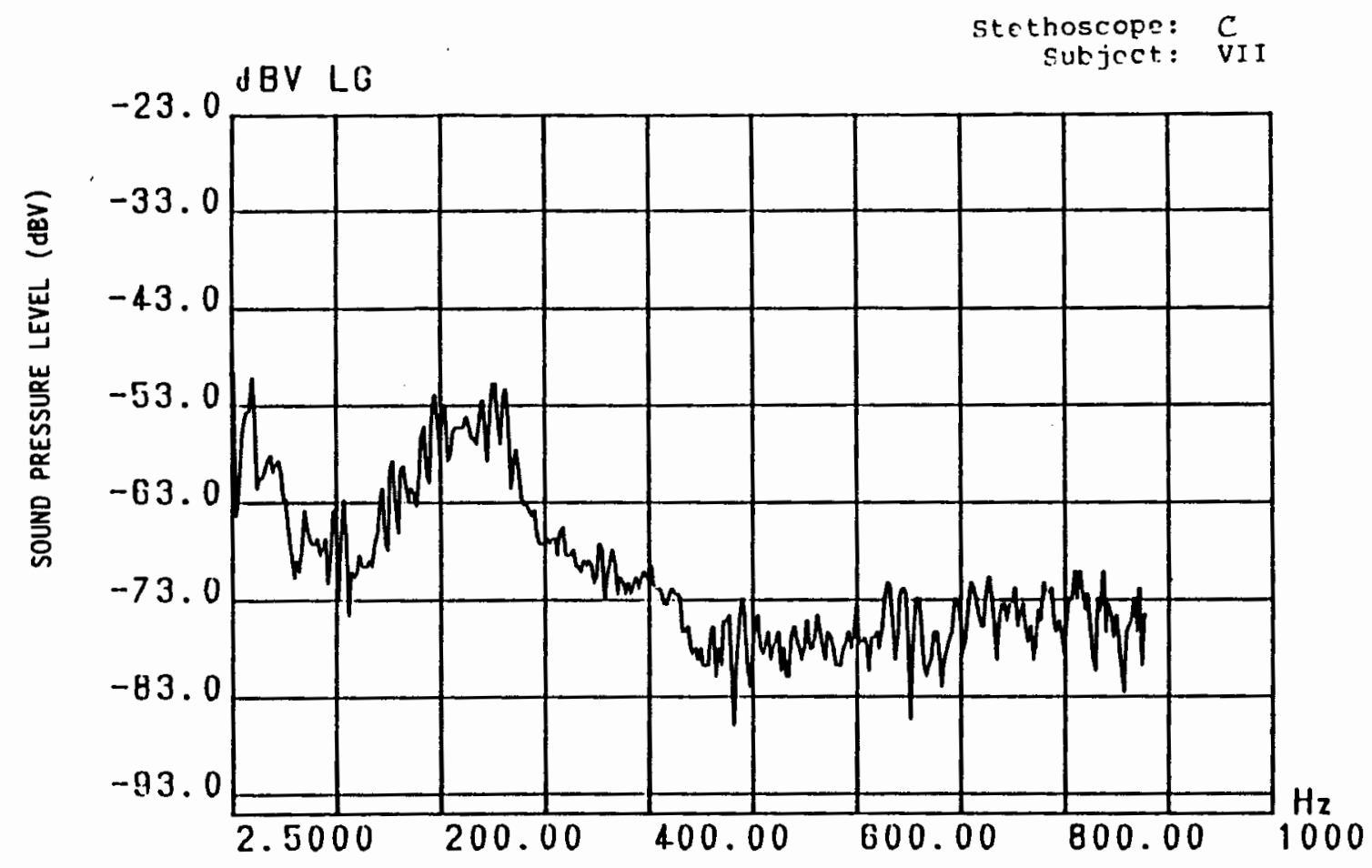

FREQUENCY $(\mathrm{Hz})$

Figure 5. Row data of emplified stethoscope $C$ at selected MCL for subject VII. 
Stethosrope: A

subject: VII

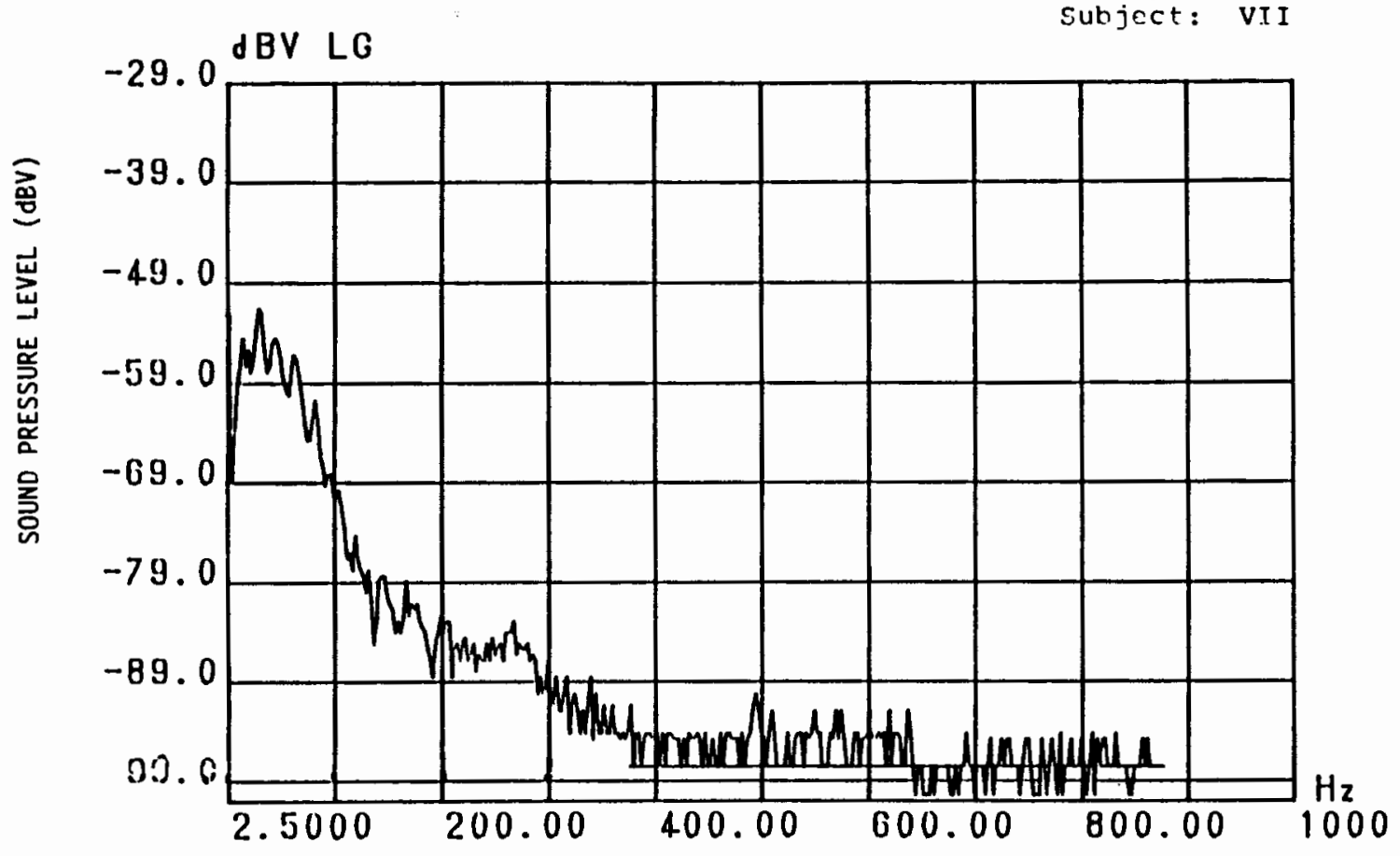

FREOUENCY ( $\mathrm{Hz}$ )

Figure 6. Raw data of acoustic stethoscope A for subject 
addition, a correction factor was made to these averages to account for the response of the microphone and the probe tubing. The actual raw data of each stethoscopes' spectrum is located in appendix $E$. The averaged sound pressure level at $50 \mathrm{~Hz}$ intervals was plotted for each stethoscope. The mean frequency response data comparing the acoustic stethoscope $A$ output and the two amplified stethoscopes, B and C, adjusted to MCL to the subject's mean threshold of audibility can be seen in Figure 7 . Overall the frequency response of the three stethoscopes are similar in that they have their greatest response below $300 \mathrm{~Hz}$. The results show that amplified stethoscope B transmits the heart sounds at the greatest SPL through $200 \mathrm{~Hz}$, from $200 \mathrm{~Hz}$ to $800 \mathrm{~Hz}$, the amplified stethoscope $C$ produced the greatest output. Acoustic stethoscope A consistently produced the lowest SPL over the frequency range except at $50 \mathrm{~Hz}$ where a marginally greater output of approximately $4 \mathrm{~dB}$ SPL over the output of stethoscope $C$ was evident.

Comparing the output of the acoustic stethoscope $A$ and the amplified stethoscope B, a range of approximately 3 to 19 dB SPL greater output was evident for stethoscope $B$, with the greatest difference in output occurring at 100 $\mathrm{Hz}$ and the least occurring at $250 \mathrm{~Hz}$. Comparing the amplified stethoscope $C$ output to the acoustic stethoscope 


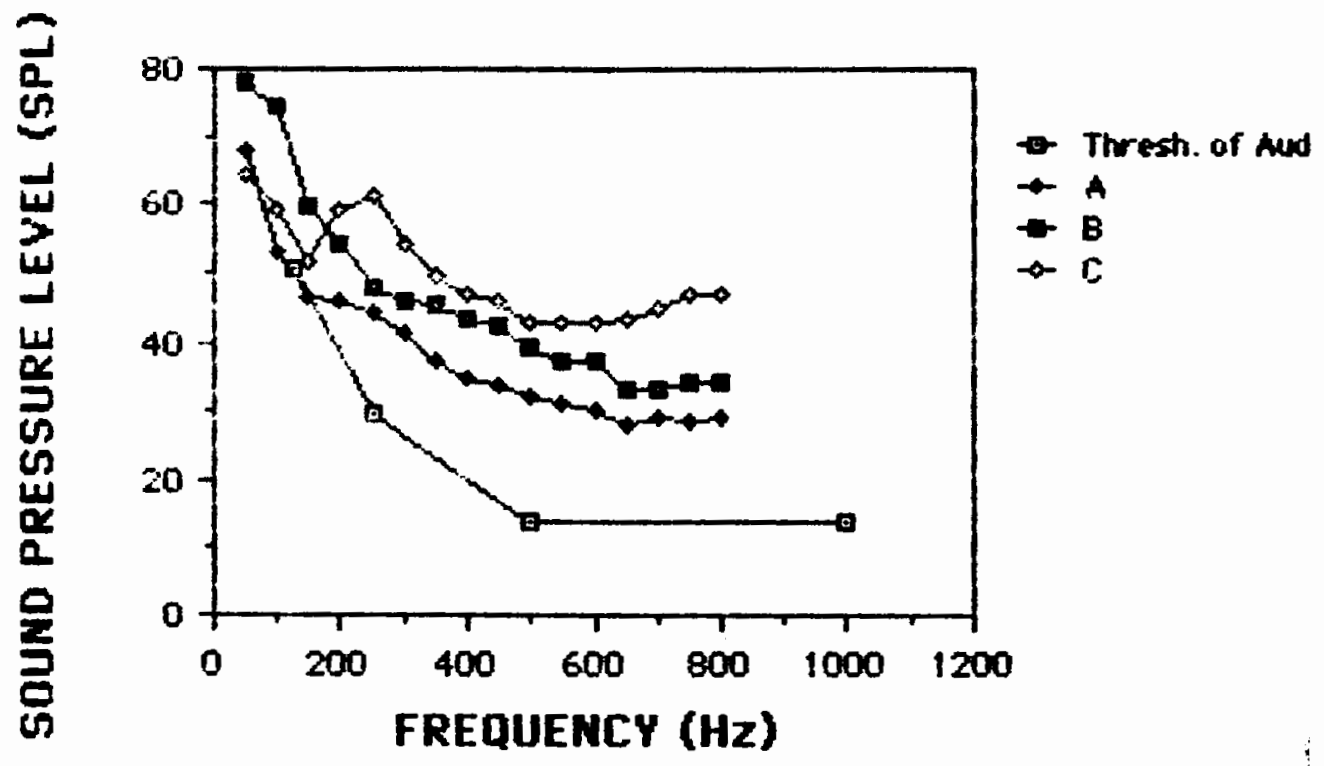

Figure 7. Mean output of three stethoscopes in dB SPL as a function of frequency. Input to the stethoscopes was a normal heart sounds. Output was measured by a probe tube system in the subject's ears. The lower curve represent the mean threshold of audibility for the subject's. 
A, a range of approximately -4 to $19 \mathrm{~dB}$ change in SPL can be seen. The greatest output occurred at $750 \mathrm{~Hz}$ and the least at $50 \mathrm{~Hz}$. In general the frequency response curves of the three stethoscopes show a primary peak, correlating with the greatest output, at $50 \mathrm{~Hz}$. A distinctive secondary peak is evident in the response of stethoscope $C$ at $250 \mathrm{~Hz}$ and a third peak at $800 \mathrm{~Hz}$. Although the frequency response curves of stethoscopes $A$ and $B$ are not characterized by distinctive peaks as stethoscope $C$, they do have a secondary increase in output at $200 \mathrm{~Hz}$ and at $350 \mathrm{~Hz}$ respectively. Mean output level and standard deviation for the three stethoscopes tested can be seen in appendix A.

Comparing the mean threshold of audibility for the 11 subjects to the mean output level of the stethoscopes tested, revealed that at $125 \mathrm{~Hz}$ stethoscope A (acoustic) presents the heart sounds to the listeners' ear just above their threshold of audibility. However, at higher frequencies stethoscope A presents the heart sounds approximately $20 \mathrm{~dB}$ above the threshold of audibility. It can be seen in Figure 7 that stethoscopes $B$ and $C$ transmit the heart sounds at greater sound pressure levels above the threshold of audibility than stethoscope A. 
CHAPTER V

\section{DISCUSSION}

The normal hearing subjects participating in this study selected a most comfortable level of loudness at a greater intensity than the maximum output of the acoustic stethoscope employed in this study. When looking at the normal threshold of audibility for frequencies $125-500 \mathrm{~Hz}$ compared to the mean frequency response of the three stethoscopes (fig. 7) it is clear that the heart sounds are lowest in level, or closer to the threshold of audibility with the acoustic stethoscope (A). Amplified stethoscope B provided the most suprathreshold energy from 50-150 $\mathrm{Hz}$ and stethoscope $\mathrm{C}$ provided the most suprathreshold energy from $200-800 \mathrm{~Hz}$.

Traditionally, MCL refers to the intensity level at which speech is most comfortable (Ventry, Rubin, \& Hill, 1971). A direct association has been demonstrated between MCL and speech intelligibility (Markle \& Zaner, 1966). That is, the process of selecting MCL is one that involves a determination of a loudness value at which speech is both comfortable and intelligible. Projecting this measure to heart sounds, it may be hypothesized that both clarity and loudness comfort were involved in listener 
judgements. If such is the case, then it would suggest that heart sounds monitored at values below MCL (stethoscope A) are less intelligible and therefore diagnostically more prone to omission errors and misinformation than sounds received at MCL (stethoscopes B and $\mathrm{C}$ ). However, the question of whether such factors as increased frequency response and greater intensity output contribute to greater validity and reliability of listener judgements concerning normal heart sounds was not addressed in this study.

The frequency-intensity domain for intelligibility of normal and pathological heart sounds is not known and merits further research. Since low frequencies contribute least to the intelligibility of speech and since heart sounds monitored through stethoscopes are low frequency dominant, it may be argued that additional research is needed to ascertain the relative contributions of frequency-intensity variables associated with intelligibility.

The acoustic stethoscope transmits normal heart sounds at approximately $5 \mathrm{~dB}$ sound pressure level above the normal threshold of audibility for $125 \mathrm{~Hz}$ and at approximately 20 to $21 \mathrm{~dB}$ sound pressure level for $250 \mathrm{~Hz}$ and $500 \mathrm{~Hz}$ respectively. In other words, for these frequencies a normal hearing person would hear this 
spectrum through an acoustic stethoscope at very low sensation levels. If the person listening to the heart sounds sustains a loss of hearing sensitivity, especially one in the lower frequencies (ie., below $800 \mathrm{~Hz}$ ), the act of detecting heart sounds through an acoustic stethoscope would be very difficult. In addition, the most comfortable level of loudness selected by a person with this type of loss would probably be greater than that selected by the normal hearing subjects.

Some of the same considerations should be evaluated in various background noise level. While the present study was accomplished in a controlled quiet environment, stethoscopes are commonly used in clinics and hospitals where unfavorable noise conditions exist. One aspect determining the efficacy of an amplified stethoscope is its' dynamic level range, another is the listener's subjective judgement of the frequency response, or the relative pitch of what is perceived as normal heart sounds.

Although the dynamic ranges of the two amplified stethoscopes are similar, the frequency response curves are quite different. The frequency response curve of stethoscope B is characterized by a smooth progression of intensity changes with a slight peak a $400 \mathrm{~Hz}$. Stethoscope C's response curve is characterized by a sharp peak at $250 \mathrm{~Hz}$ and a smooth peak at $750 \mathrm{~Hz}$. Although a 
quantitative scoring of stethoscope quality was not solicited from the subjects, a large majority of them volunteered a positive quality judgement consistent with the smooth response curve of stethoscope B. A more systematic look at the preferential selection of stethoscopes based on the qualitative relationship between judgements and spectral analysis may provide valuable information for manufactures of amplified stethoscopes.

During initial placement of stethoscopes on subjects, it was necessary to adjust the eartips to either alleviate discomfort or enhance sound transmission. Groom (1959) reported a reduction in sound transmission resulting from a poor coupling of the eartips to the ear canal. Rappaport \& Sprague (1952) and Littman (1972) noted the point at which the eartips enter the ear canal as a point of common sound leakage. Custom made earmolds for each subject would likely reduce discomfort and sound leakage, thereby enhancing sound transmission. This variable should be investigated as well.

Further investigations may thus be beneficial in the following areas: 1. The affect of custom fit earmolds on sound leakage. 2. How does the most comfortable level selected by the listeners vary with different noise conditions? 3. How do subjects, particularly experienced listeners, rate the quality of stethoscope in relationship 
to their acoustical properties? 4. Does the increase in frequency response and greater intensity output contribute to greater validity and reliability of listener judgments concerning normal heart sounds? 
CHAPTER VI

\section{SUMMARY}

This study investigated the following questions: 1) What is the spectra of human heart sounds when transmitted to the listener's ear through amplified and acoustic stethoscopes? 2) How does the acoustic spectrum of normal heart sounds compare to the threshold of audibility for normal hearing sensitivity? 3) Do normal hearing listeners elect to listen to heart sounds at a higher intensity than the acoustic stethoscope is able to transmit?

Eleven normal hearing adults (six females and five males) served as 1 istening subjects for evaluating the stethoscopes with normal heart sounds from a young adult male model as the input signal.

A probe microphone was situated at the entrance of each subject's ear canal, and the output transmitted by each stethoscope was measured by a Rockland Fast Fourier Transform Analyzer. The output of normal heart sounds, transmitted by the amplified stethoscopes, was measured at a level selected as most comfortable, while maximum output was measured for the acoustic stethoscope.

Comparison of the mean outputs of the three 
stethoscopes suggested that the level that was most comfortable for auscultation of normal heart sounds was greater then the maximum output of the acoustic stethoscope. Since the acoustic stethoscope is the most universally employed in medical settings, this investigation raises questions about its psychoacoustic efficacy for monitoring human heart sounds when compared to amplified stethoscopes. 
REFERENCES

American National Standards Institute, (1969).

Specifications for Audiometers. ANSI S3.6-1969. New York: American National standards Institute.

Cabot, R. C., \& Dodge, H. F. (1925). Frequency characteristics of heart and lung sounds. The Journal of the American Medical Association, 84, $\overline{1793-179} \overline{6}$

Ertel, P. Y., Lawrence, M., Brown, R. K., \& Stern, A. M. (1966a). Stethoscope acoustics: I. The doctor and his stethoscope. Circulation, 34, 889-898.

Ertel, P. Y., Lawrence, M., Brown, R. K., \& Stern, A. M. (1966b). Stethoscope acoustics: II. Transmission and filtration patterns. Circulation, 34, 899-909.

Ewertsen, H. W., Ipsen, J. B., \& Nielsen, S. S. (1957). On acoustical characteristics of the earmould. Acta otolaryngol, 47, 312-317.

Fletcher, H., \& Munson, W. A. (1933). Loudness, its definition, measurement and calculation. Journal of the Acoustic Society of America, 5, 82-108.

Fredrick, H. A., \& Dodge, H. F. (1924). The stethophone, An electrical stethoscope. The Bell system Technical Journal, 3, 531-549.

Gamble, C. J., \& Replogle, D. E. (1924). A multiple electrical stethoscope for teaching. Journal of American Medical Association, 82, 387-388.

Gilman, S., Dirks, D. D., \& Stern, R. (1981). The effect of occluded ear impedances on the eardrum SPL produced by hearing aids. Journal of the Acoustic Society of America, 70, 370-386.

Gilman, S., \& Dirks, D. D. (1984). A probe earmold system for. measuring eardrum SPL under hearing-aid conditions. Scandinavian Audiology, 13, 15-22. 
Groom, D. (1956). The effect of background noise on cardiac auscultation. American Heart Journal, 52, $781-790$.

Groom, D., \& Chapman, w. (1959). Anatomic variations of the auditory canal pertaining to the fit of stethoscope earpieces. Circulation, 19, 606-608.

Groom, D. (1964). Comparative efficiency of stethoscopes. American Heart Journal, 68, 220-226.

Harford, E. (1980). The use of a miniature microphone in the ear canal for the verification of hearing aid performance. Ear and Hearing, 1, 329-337.

Johnston, F. D., \& Kline, E. H. (1940). An acoustical study of the stethoscope. Archive of Internal Medicine, 65, 328-339.

Kindig, J. R., Beeson, R. P., Campbell, R. W., Andries, F., \& Tavel, M. (1982). Acoustical performance of the stethoscope: A comparative analysis. Cirriculum in Cardiology, 104, 269-275.

Littmann, D. (1972). Ausculation. American Journal of Nursing, 1239-1241.

Markle, D. M., \& Zaner, A. (1966). The determination of "gain requirements" of hearing aids: A new methods. Journal of Auditory Research, 6, 371-377.

McDonald, F. D., \& Studebaker, G. A. (1970). Earmold alteration effects as measured in the human auditory meatus. Journal of the Acoustic Society of America, $48,1366-\overline{1372 .}$

Rappaport, M. B., \& Sprague, H. B. (1941). Physiologic and physical laws that govern auscultation, and their clinical application. The American Heart Journal, 21, 257-309.

Rappaport, M. B., \& Sprague, H. B. (1951). The effects of tubing bore on stethoscope efficiency. American Heart Journal, 42, 605-609.

Rappaport, M. R., \& Sprague, H. B. (1952). The effects of improper fitting of stethoscope to ears of auscultatory efficiency. American Heart Journal, 43, 713-715. 
Richard, J. D. (1956). Frequency spectra of some normal heart sounds. American Heart Journal, 53, 183-192.

Sakula, A. (1981). RTH Laennec 1781-1826 His life and work: a bicentenary appreciation. Thorax, 36, 81-90.

Shaw, E. A. G. (1966). Earcanal pressure generated by a free sound field. Journal of the Acoustical Society of America, 39, 465-470.

Shaw, E. A. G., \& Lawton, B. W. (1982). Estimation of acoustical energy reflectance at the eardrum from measurements of pressure distribution in the human ear canal. Journal of the Acoustic Society of America, 72, 766-773.

Sivian, L. J., \& White, S. D. (1933). On minumun audible sound fields. Journal of the Acoustic Society of America, 4, 288-321.

Ventry, I. M., woods, R. W., Rubin, M., \& Hill, W. (1971). Most comfortable loudness for pure tones, noise and speech. Journal of the Acoustic Society of America, $\underline{49}, 1805-1813$.

Von Bekesy, G. (1960). Auditory Thresholds. In E. G. Wever (Ed.), Experiments in hearing (257-261). New York: McGraw-Hill.

Wiener, F. M., \& Ross, D. A. (1946). Pressure distribution in the auditory canal. Journal of the Acoustic Society of America, 18, 401-408.

Williams, H. B., \& Dodge, H. F. (1926). Analysis of heart sounds. Archives of Internal Medicine, 38 , 685-693.

Zemplenyi, J., Dirks, D., \& Gilman, S. (1985). Probedetermined hearing-aid gain compared to functional and coupler gains. Journal of speech and Hearing Research, 28, 394-404. 
THE AVERAGE SPL AND STANDARD DEVIATION FOR THE OUTPUT OF STETHOSCOPES A, B AND C AT SELECTED FREQUENCIES WITH CORRECTION FOR FREQUENCY RESPONSE OF PROBE TUBE AND MICROPHONE INCLUDED

Frequency: lst $\quad 50 \quad 100 \quad 150 \quad 200 \quad 250$

Stethoscope

A

$\begin{array}{lllllll}\bar{x} & 72.0 & 68.0 & 53.0 & 46.5 & 46.0 & 44.3\end{array}$

$\begin{array}{lllllll}\text { sd } & 10.63 & 7.47 & 11.11 & 8.13 & 10.30 & 10.36\end{array}$

Stethoscope

B

$\begin{array}{lcccccc}\overrightarrow{\mathrm{x}} & 74.0 & 78.0 & 74.4 & 59.5 & 54.2 & 48.0 \\ \text { sd } & 8.06 & 11.44 & 11.55 & 10.93 & 10.99 & 10.22\end{array}$

Stethoscope

C

$\begin{array}{lcccccc}\overline{\mathrm{x}} & 67.0 & 64.1 & 59.3 & 51.5 & 59.0 & 61.0 \\ \text { sd } & 5.12 & 6.84 & 12.24 & 12.92 & 14.59 & 12.14\end{array}$


Frequency: $\quad 300 \quad 350 \quad 400 \quad 450 \quad 500 \quad 550$

Stethoscope

A

$\begin{array}{lllllll}\overline{\mathbf{x}} & 41.1 & 37.1 & 34.5 & 33.8 & 32.0 & 31.3 \\ \text { sd } & 11.64 & 10.82 & 11.33 & 11.36 & 7.63 & 10.85\end{array}$

Stethoscope

B

$\overrightarrow{\mathrm{x}}$

$\begin{array}{llllll}46.0 & 45.3 & 43.5 & 42.5 & 39.0 & 37.1\end{array}$

sd

$11.73 \quad 11.22 \quad 10.23 \quad 10.66$

$8.70 \quad 8.33$

Stethoscope

C

$\mathbf{x}$

sd $\begin{array}{llllll}54.0 & 49.4 & 46.7 & 45.7 & 43.0 & 43.0\end{array}$

$\begin{array}{llllll}12.02 & 12.52 & 11.34 & 11.50 & 10.08 & 10.91\end{array}$ 
Frequency:

600

650

700

750

800

Stethosocpe

A

$\overrightarrow{\mathbf{x}}$

30.0

28.0

29.1

28.4

29.1

sd

9.0

9.63

3.79

8.55

8.31

Stethoscope

B

$\overrightarrow{\mathbf{x}}$

sd

Stethoscope

$\overline{\mathrm{x}}$

s
37.0

8.68

33.3

7.07

C

43.0

43.4

45.0

47.1

47.0

10.72

10.52

11.45

9.75

9.73 
OUTPUT LEVELS IN AB SPL FOR INDIVIDUAL EARS OBTAINED WITH STETHOSCOPE A

\begin{tabular}{crrrrrr} 
Frequency: & Ist & \multicolumn{1}{l}{50} & 100 & 150 & 200 & 250 \\
Subject & & & & & & \\
I & 70.0 & 57.5 & 42.5 & 37.5 & 32.6 & 35.0 \\
II & 62.5 & 57.5 & 45.0 & 35.0 & 30.0 & 35.0 \\
III & 73.6 & 71.1 & 41.1 & 50.1 & 43.6 & 38.6 \\
IV & 78.6 & 63.6 & 60.1 & 50.1 & 41.1 & 41.1 \\
V & 74.6 & 62.1 & 39.6 & 42.1 & 39.6 & 39.6 \\
VI & 82.1 & 62.1 & 47.1 & 47.1 & 49.6 & 47.1 \\
VII & 68.6 & 61.1 & 51.1 & 41.1 & 38.6 & 33.6 \\
VIII & 47.5 & 55.0 & 35.0 & 30.0 & 27.5 & 27.5 \\
IX & 86.1 & 66.1 & 48.6 & 48.6 & 48.6 & 41.1 \\
X & 66.1 & 71.1 & 68.6 & 56.1 & 56.1 & 61.1 \\
XI & 78.0 & 65.0 & 45.0 & 42.5 & 40.0 & 32.5 \\
Total SPL & 787.7 & 692.2 & 523.7 & 480.2 & 447.3 & 432.2 \\
Mean SPL & 72.0 & 63.0 & 48.0 & 44.0 & 41.0 & 39.3 \\
Corrected & 72.0 & 68.0 & 53.0 & 45.5 & 46.0 & 44.3 \\
SPL & & & & & &
\end{tabular}




\section{Frequency
Subject}

I

40.0

28.0

25.0

22.5

27.5

27.5

I I

27.5

22.5

22.5

27.5

27.5

27.5

I I I

33.6

31.1

31.1

31.1

33.6

28.6

IV

39.0

31.1

28.6

28.6

31.1

31.1

$\mathrm{V}$

34.6

29.6

32.1

27.1

29.6

27.1

VI

39.6

39.6

39.6

39.6

32.1

27.1

VII

33.5

28.6

26.1

26.1

28.6

28.6

VIII

25.0

22.5

22.5

22.5

25.0

25.0

IX

33.6

36.1

33.6

33.6

31.1

31.1

$\mathrm{X}$

63.6

56.1

61.1

61.1

53.6

63.6

$X I$

27.5

27.5

27.5

25.0

30.0

27.5

Total SPL

387.5

352.7

349.7

344.7

349.7

344.7

Mean SPL

36.1

32.1

32.0

31.3

32.0

31.3

Corrected

41.1

37.1

34.5

33.8

32.0

31.3 
Frequenc
Subject

I

I I

III

IV

V

VI

VII

VII I

IX

$\mathrm{X}$

$X I$

Total SPL

Mean SPL

Corrected

SPL

600

650

700

750

800

850

$$
25.0
$$

22.5

25.0

25.0

25.0

50.0

$25.0 \quad 28.0$

28.0

28.0

28.0

28.5

32.1

28.6

28.6

28.6

28.6

51.1

28.6

26.1

28.6

26.1

28.6

27.1

27.1

27.1

27.1

29.6

27.1

27.1

23.6

23.6

27.

23.6

25.0

22.5

22.5

28.6

26.1

28.6

53.6

56.1

53.

25.0

25.0

53.6

25.0

N R

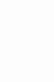

ce

cor




\section{APPENDIX C}

OUTPUT LEVELS IN $d B$ SPL FOR INDIVIDUAL EARS OBTAINED WITH STETHOSCOPE B

Frequency: $\quad$ lst $\quad 50 \quad 100 \quad 150 \quad 200 \quad 250$

Subject

$\begin{array}{lllllll}\text { I } & 66.1 & 63.6 & 63.6 & 51.1 & 41.1 & 41.1 \\ \text { II } & 67.1 & 67.1 & 64.6 & 49.6 & 44.6 & 39.6 \\ \text { III } & 68.6 & 71.1 & 58.6 & 48.6 & 33.6 & 33.6 \\ \text { IV } & 71.1 & 61.1 & 68.6 & 51.1 & 43.6 & 38.6 \\ \text { V } & 72.1 & 69.6 & 67.1 & 57.1 & 52.1 & 32.1 \\ \text { VI } & 81.1 & 81.1 & 76.1 & 61.1 & 58.6 & 58.6 \\ \text { VII } & 75.0 & 80.0 & 75.0 & 55.0 & 47.5 & 47.5 \\ \text { VIII } & 77.5 & 77.5 & 72.5 & 65.0 & 55.0 & 40.0 \\ \text { IX } & 83.6 & 88.6 & 86.1 & 73.6 & 63.6 & 53.6 \\ \text { X } & 60.0 & 57.5 & 50.0 & 40.0 & 40.0 & 35.0 \\ \text { XI } & 86.1 & 83.6 & 81.1 & 73.6 & 61.1 & 48.6\end{array}$

$\begin{array}{lllllll}\text { Total SPL } & 808.3 & 800.8 & 763.3 & 625.8 & 540.8 & 468.3\end{array}$ $\begin{array}{lllllll}\text { Mean SPL } & 74.0 & 73.0 & 69.4 & 57.0 & 49.2 & 43.0\end{array}$ $\begin{array}{lllllll}\text { Corrected } & 74.0 & 78.0 & 74.4 & 59.5 & 54.2 & 48.0\end{array}$ SPL 
Frequency: $\quad 300 \quad 350 \quad 400 \quad 450 \quad 500 \quad 550$

Subject

$\begin{array}{lllllll}\text { I } & 31.1 & 33.6 & 36.1 & 38.6 & 41.1 & 31.1 \\ \text { II } & 34.6 & 34.6 & 34.6 & 36.6 & 32.1 & 32.1 \\ \text { III } & 33.6 & 33.6 & 28.6 & 26.1 & 33.6 & 33.6 \\ \text { IV } & 36.1 & 36.1 & 33.6 & 31.1 & 31.1 & 28.6 \\ \text { V } & 34.6 & 34.6 & 39.6 & 37.1 & 32.1 & 32.1 \\ \text { VI } & 58.6 & 56.1 & 51.1 & 48.6 & 46.1 & 43.6 \\ \text { VII } & 47.5 & 42.5 & 45.0 & 40.0 & 40.0 & 42.5 \\ \text { VIII } & 40.0 & 42.5 & 42.5 & 42.5 & 42.5 & 42.5 \\ \text { IX } & 56.1 & 56.1 & 56.1 & 53.6 & 53.6 & 51.1 \\ \text { X } & 27.5 & 25.0 & 27.5 & 25.0 & 25.0 & 25.0 \\ \text { XI } & 46.1 & 48.6 & 53.6 & 56.1 & 48.6 & 46.1\end{array}$

$\begin{array}{lllllll}\text { Total SPL } & 445.8 & 443.3 & 448.3 & 435.3 & 425.8 & 408.3\end{array}$

$\begin{array}{lllllll}\text { Mean SPL } & 41.0 & 40.3 & 41.0 & 40.0 & 39.0 & 37.1\end{array}$

$\begin{array}{lllllll}\text { Corrected } & 46.0 & 45.3 & 43.5 & 42.5 & 39.0 & 37.1\end{array}$ SPL 


$\begin{array}{cllllll}\text { Frequency: } & 600 & 650 & 700 & 750 & 800 & 850 \\ \text { Subject } & & & & & & \\ \text { I } & 36.1 & 31.1 & 31.1 & 28.6 & 28.6 & 26.1 \\ \text { II } & 32.1 & 27.1 & 27.1 & 27.1 & 32.1 & 27.1 \\ \text { III } & 33.6 & 28.6 & 26.1 & 28.6 & 31.1 & 28.6 \\ \text { IV } & 28.6 & 26.1 & 26.1 & 28.6 & 28.6 & \text { NR } \\ \text { V } & 27.1 & 27.1 & 27.1 & 27.1 & 27.1 & 27.1 \\ \text { VI } & 41.1 & 41.1 & 41.1 & 41.1 & 41.1 & 41.1 \\ \text { VII } & 42.6 & 40.0 & 40.0 & 35.0 & 35.0 & \text { NR } \\ \text { VIII } & 40.0 & 35.0 & 35.0 & 35.0 & 35.0 & 35.0 \\ \text { IX } & 51.1 & 43.6 & 46.1 & 51.1 & 48.6 & \text { NR } \\ \text { X } & 22.5 & 25.0 & 25.0 & 25.0 & 22.5 & 25.0 \\ \text { XI } & 46.1 & 41.1 & 41.1 & 41.1 & 41.1 & \text { NR } \\ \text { Total SPL } & 400.9 & 365.8 & 365.8 & 368.3 & 370.8 & \\ \text { Mean SPL } & 37.0 & 33.3 & 33.3 & 34.0 & 34.0 & \\ \text { Corrected } & 37.0 & 33.3 & 33.3 & 34.0 & 34.0 & \\ \text { SPL } & & & & & & \end{array}$




\section{APPENDIX D}

OUTPUT LEVELS IN AB SPL FOR INDIVIDUAL EARS OBTAINED WITH STETHOSCOPE C

$\begin{array}{crrrrrr}\text { Frequency: } & \text { Ist } & 50 & 100 & 150 & 200 & 250 \\ \text { Subject } & & & & & & \\ \text { I } & 60.0 & 55.0 & 52.5 & 52.5 & 65.0 & 65.0 \\ \text { II } & 63.6 & 56.1 & 41.1 & 33.6 & 28.5 & 41.1 \\ \text { III } & 66.1 & 58.6 & 53.6 & 38.6 & 38.6 & 48.6 \\ \text { IV } & 77.5 & 65.0 & 72.5 & 75.0 & 75.0 & 75.0 \\ \text { V } & 64.6 & 57.1 & 49.1 & 34.6 & 44.6 & 52.1 \\ \text { VI } & 66.1 & 68.6 & 68.6 & 56.1 & 56.1 & 61.1 \\ \text { VII } & 69.6 & 62.1 & 57.1 & 57.1 & 67.1 & 69.6 \\ \text { VIII } & 64.6 & 57.1 & 57.1 & 54.1 & 54.6 & 47.1 \\ \text { IX } & 48.6 & 61.1 & 51.1 & 46.1 & 43.6 & 41.1 \\ \text { X } & 35.0 & 52.5 & 45.1 & 30.0 & 22.5 & 30.0 \\ \text { XI } & 49.6 & 47.1 & 57.1 & 52.1 & 47.1 & 47.1 \\ \text { Total SPI } & 535.3 & 590.2 & 612.9 & 540.3 & 487.8 & 485.7 \\ \text { Mean SPL } & 49.0 & 54.0 & 56.0 & 49.1 & 44.4 & 44.2 \\ \text { Corrected } & 51.5 & 59.0 & 61.0 & 54.0 & 49.4 & 46.7 \\ \text { SPL } & & & & & & \end{array}$




$\begin{array}{lrrrrrr}\text { Frequency: } & 300 & 350 & 400 & 450 & 500 & 550 \\ \text { Subject } & & & & & & \\ \text { I } & 57.5 & 55.0 & 47.5 & 50.0 & 50.0 & 50.0 \\ \text { II } & 41.1 & 31.1 & 28.5 & 28.5 & 31.1 & 31.1 \\ \text { III } & 46.1 & 41.1 & 36.1 & 36.1 & 33.6 & 36.1 \\ \text { IV } & 67.5 & 60.0 & 62.5 & 62.5 & 60.0 & 60.0 \\ \text { V } & 42.1 & 42.1 & 40.1 & 37.1 & 34.6 & 34.6 \\ \text { VI } & 63.6 & 56.1 & 61.1 & 58.6 & 53.6 & 58.6 \\ \text { VII } & 52.1 & 52.1 & 49.6 & 39.6 & 44.6 & 44.6 \\ \text { VIII } & 42.1 & 37.1 & 42.1 & 47.1 & 44.6 & 44.6 \\ \text { IX } & 46.1 & 43.6 & 41.1 & 41.1 & 41.1 & 41.1 \\ \text { X } & 30.0 & 22.5 & 30.0 & 27.5 & 27.5 & 25.0 \\ \text { XI } & 52.1 & 47.1 & 47.1 & 47.1 & 47.1 & 47.1 \\ \text { Total SPL } & 540.3 & 487.8 & 485.7 & 475.2 & 467.8 & 472.8 \\ \text { Mean SPL } & 49.1 & 44.4 & 44.2 & 43.2 & 43.0 & 43.0 \\ \text { Corrected } & 54.0 & 49.4 & 46.7 & 45.7 & 43.0 & 43.0 \\ \text { SPL } & & & & & & \end{array}$


Frequency:

600

650

700

750

800

850

Subject

I

I I

I I I

IV

V

VI

VII

VI I I

IX

$\mathrm{X}$

XI

Total SPL

Mean SPL

Corrected

SPL
50.0

47.5

55.0

55.0

52.5

20.0

28.5

28.5

28.5

31.1

28.

31.1

36.1

33.6

46.1

41.1

28.6

$60.0 \quad 60.0$

62.5

62.5

65.0

26.1

34.6

34.6

39.6

42.1

42.1

27.1

$53.6 \quad 56.1$

56.1

53.6

53.6

23.6

47.1

47.1

47.1

47.1

44.6

47.1

52.1

49.6

48.5

$43.6 \quad 46.1$

48.6

48.6

53.6

NR

27.5

27.5

27.5

30.0

35.0

NR

$47.1 \quad 47.1$

49.6

49.6

47.1

467.7

477.7

495.2

517.8

512.6

43.0

43.4

45.0

47.1

47.0

43.0

43.4

45.0

47.1

47.0 


\section{APPENDIX $\Sigma$}

FRECUENCY RESPONSE CURVES EY SURJECT FOF STETHCSCOPES A. (ACOUSTIC), B AND C (AMPLIFIED); TEIS REPRESENTS AN AVERAGE SPECTRUH RECCFDED OVER 60 SECONDS
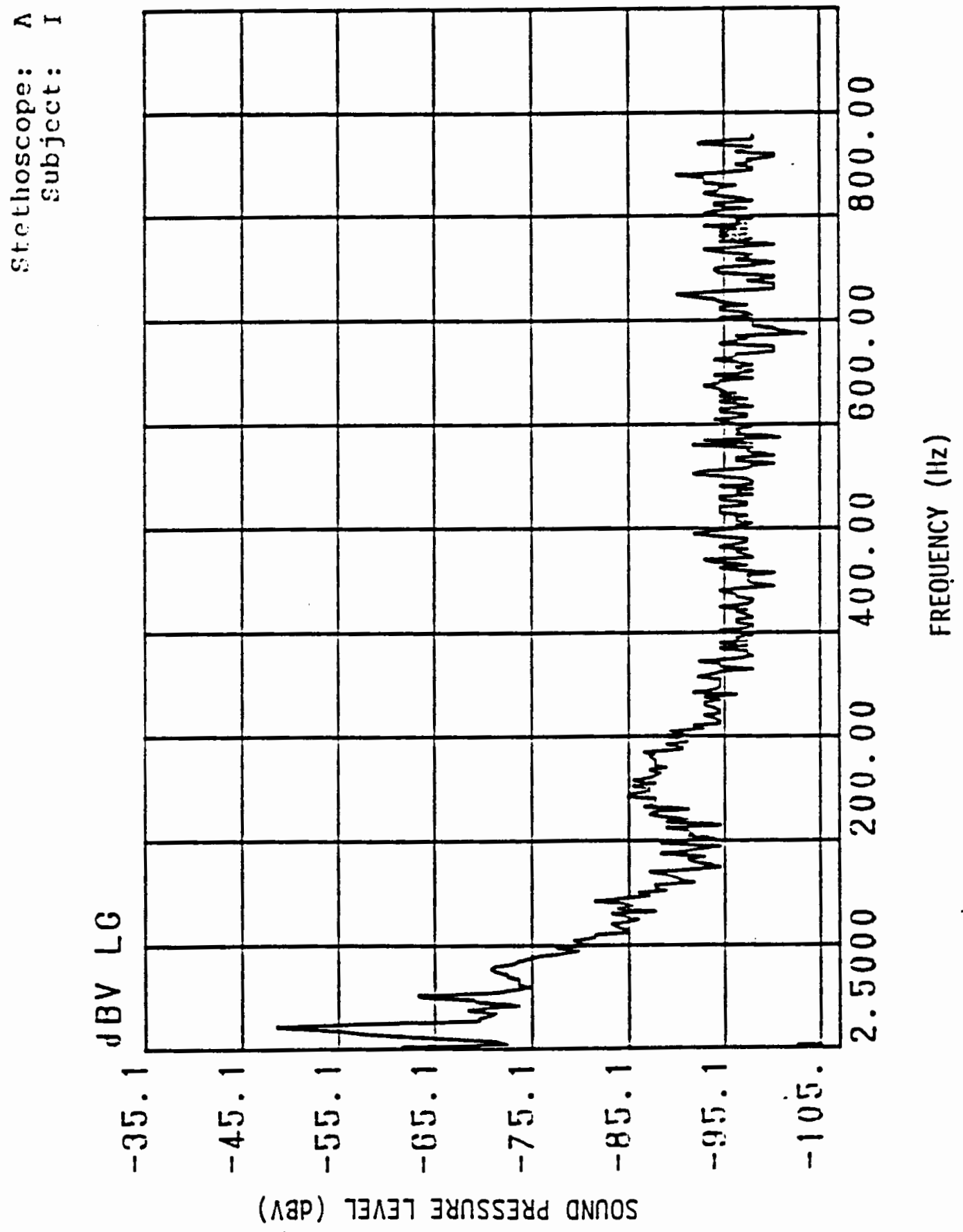


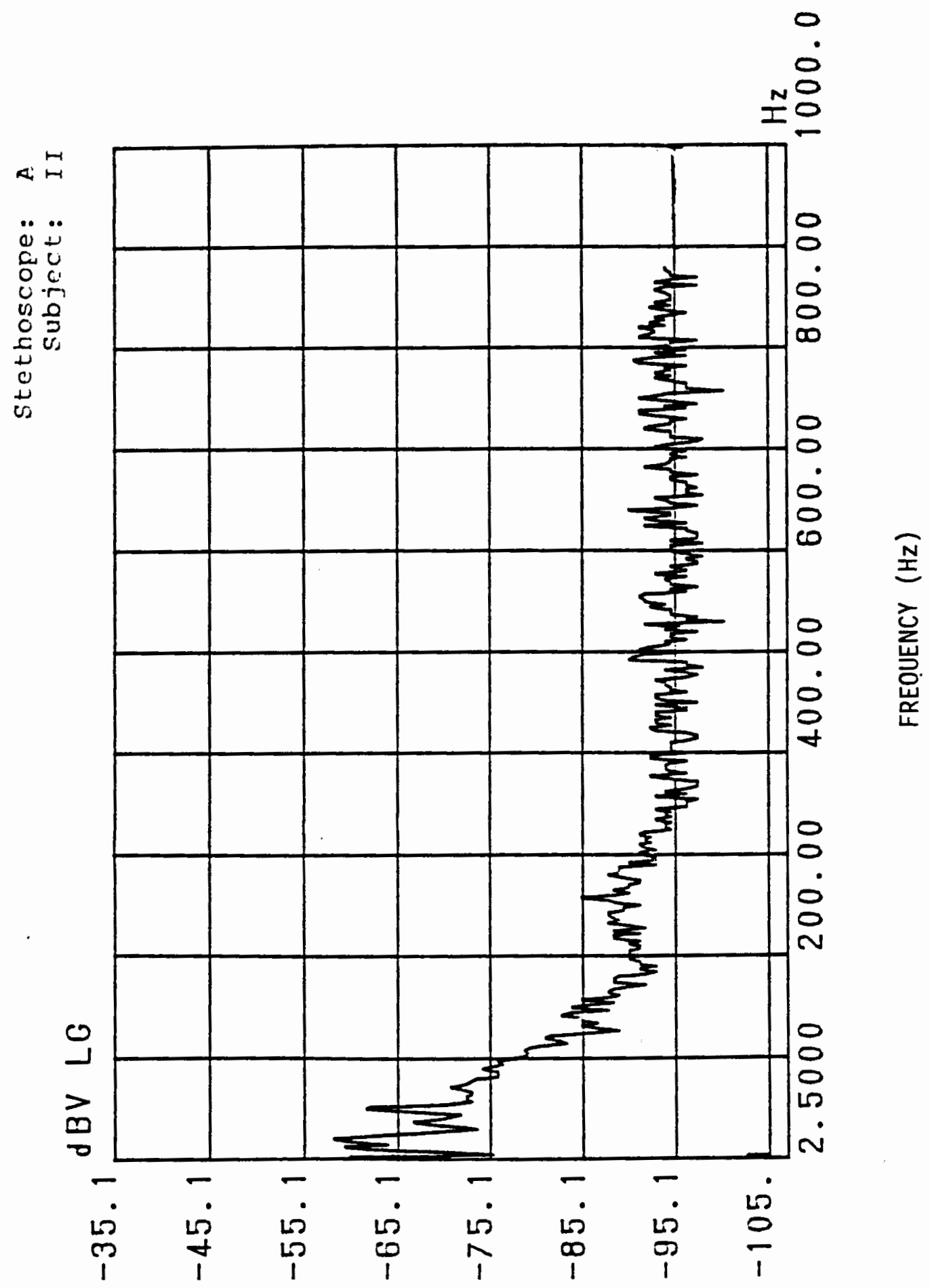

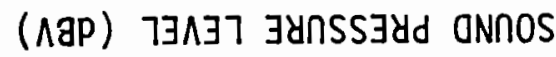




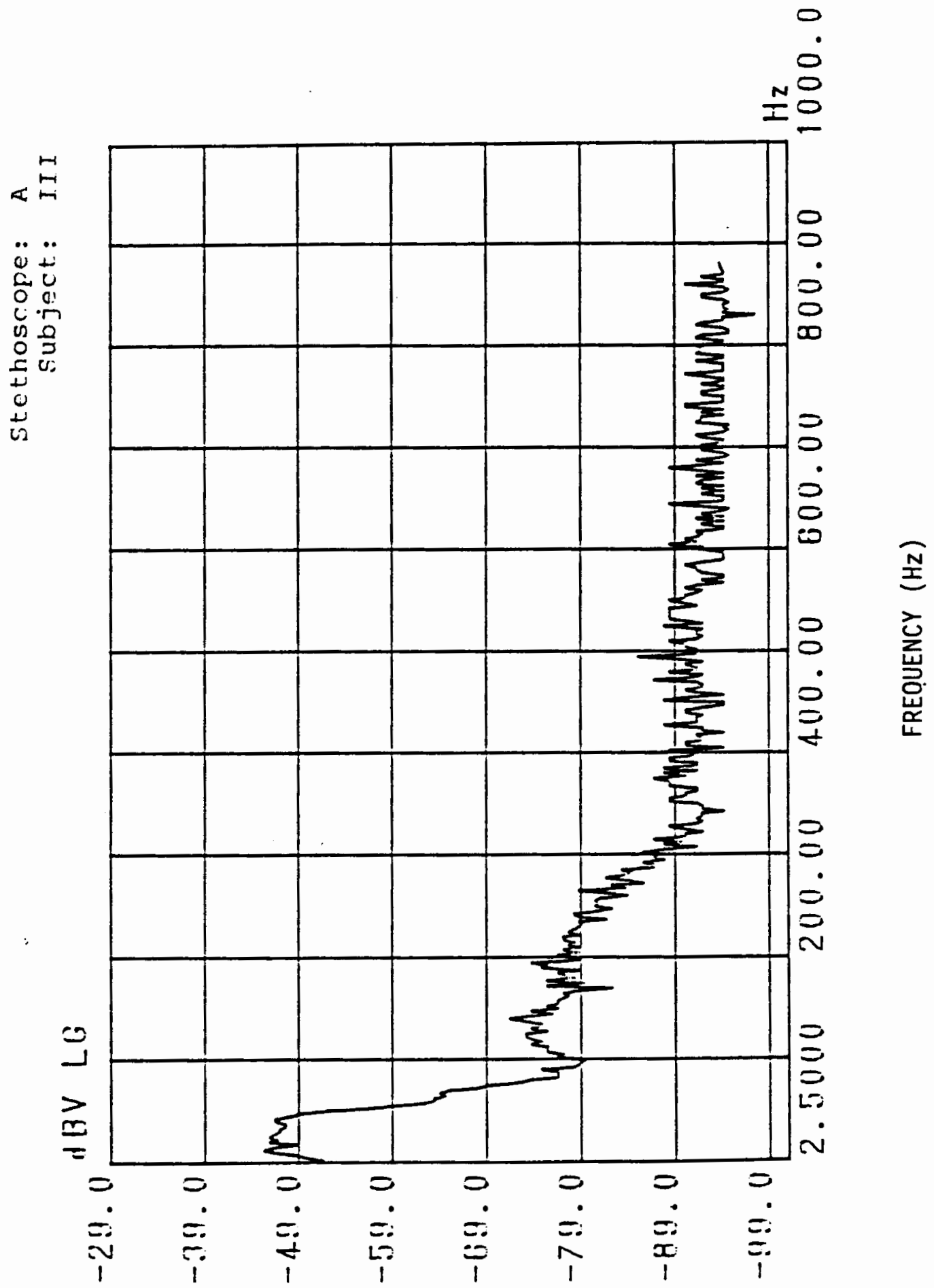

( 


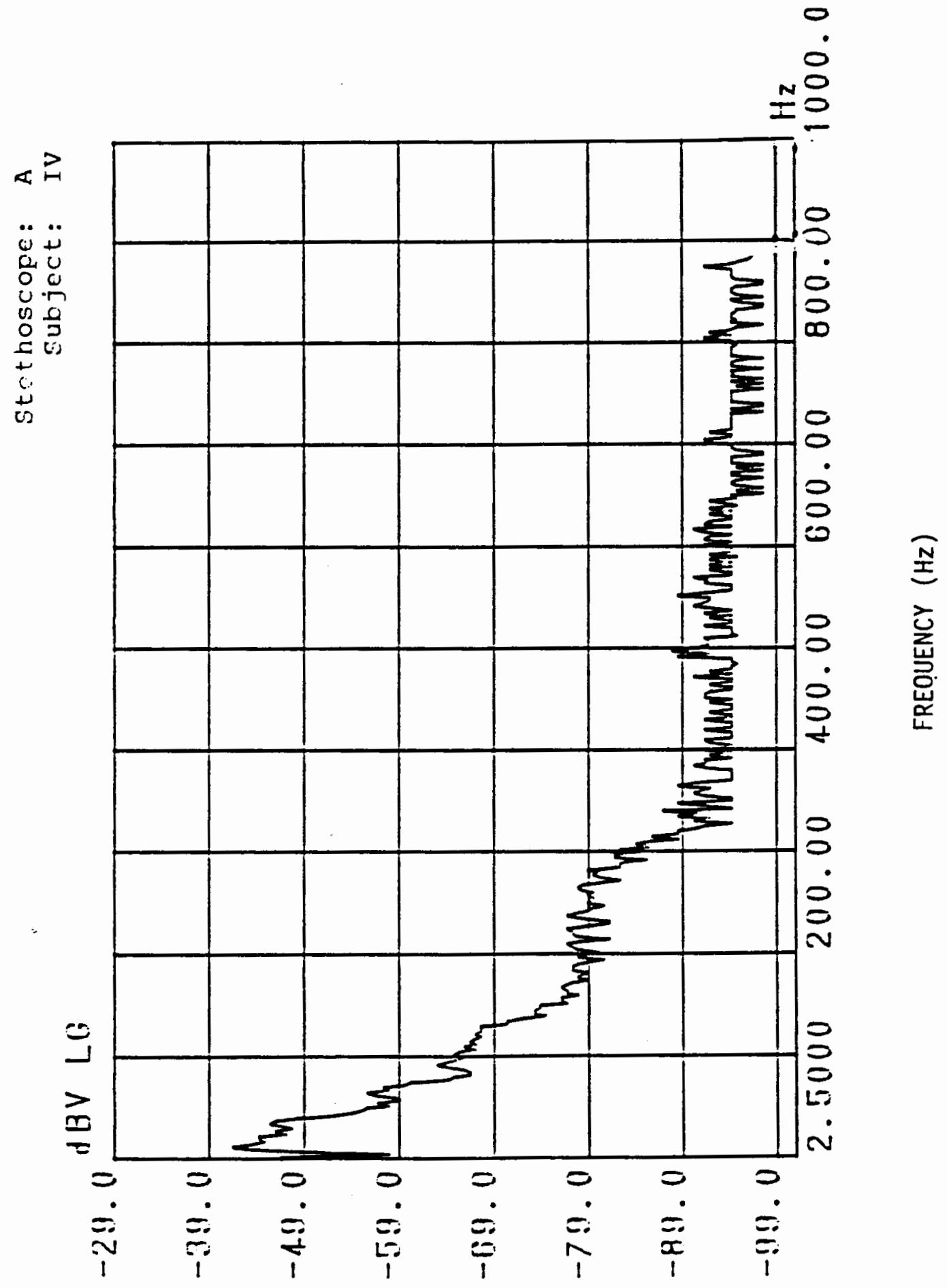

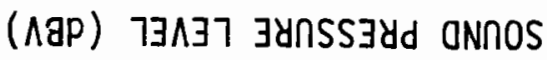




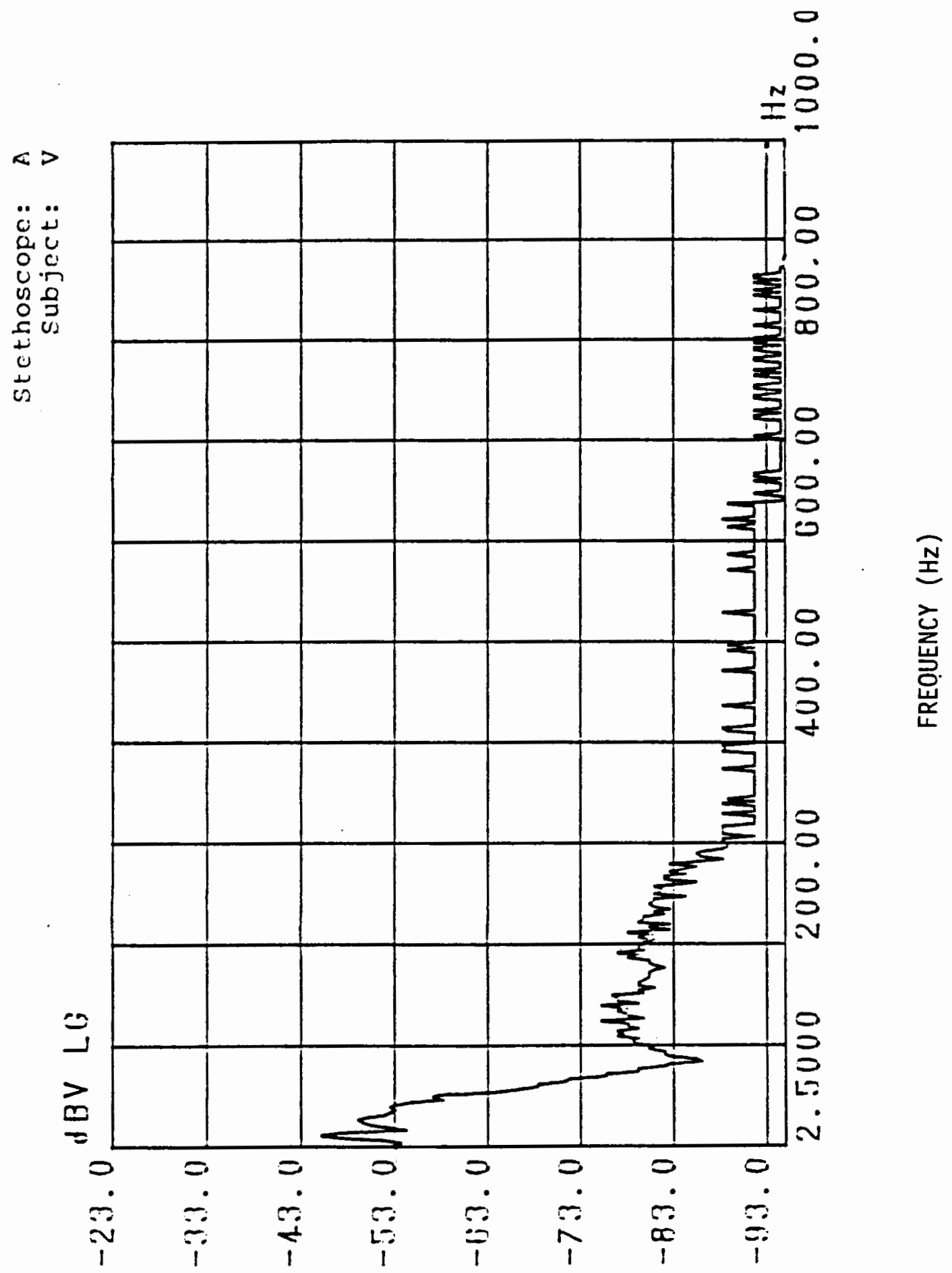

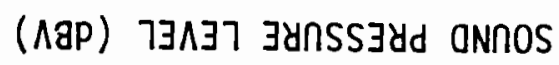




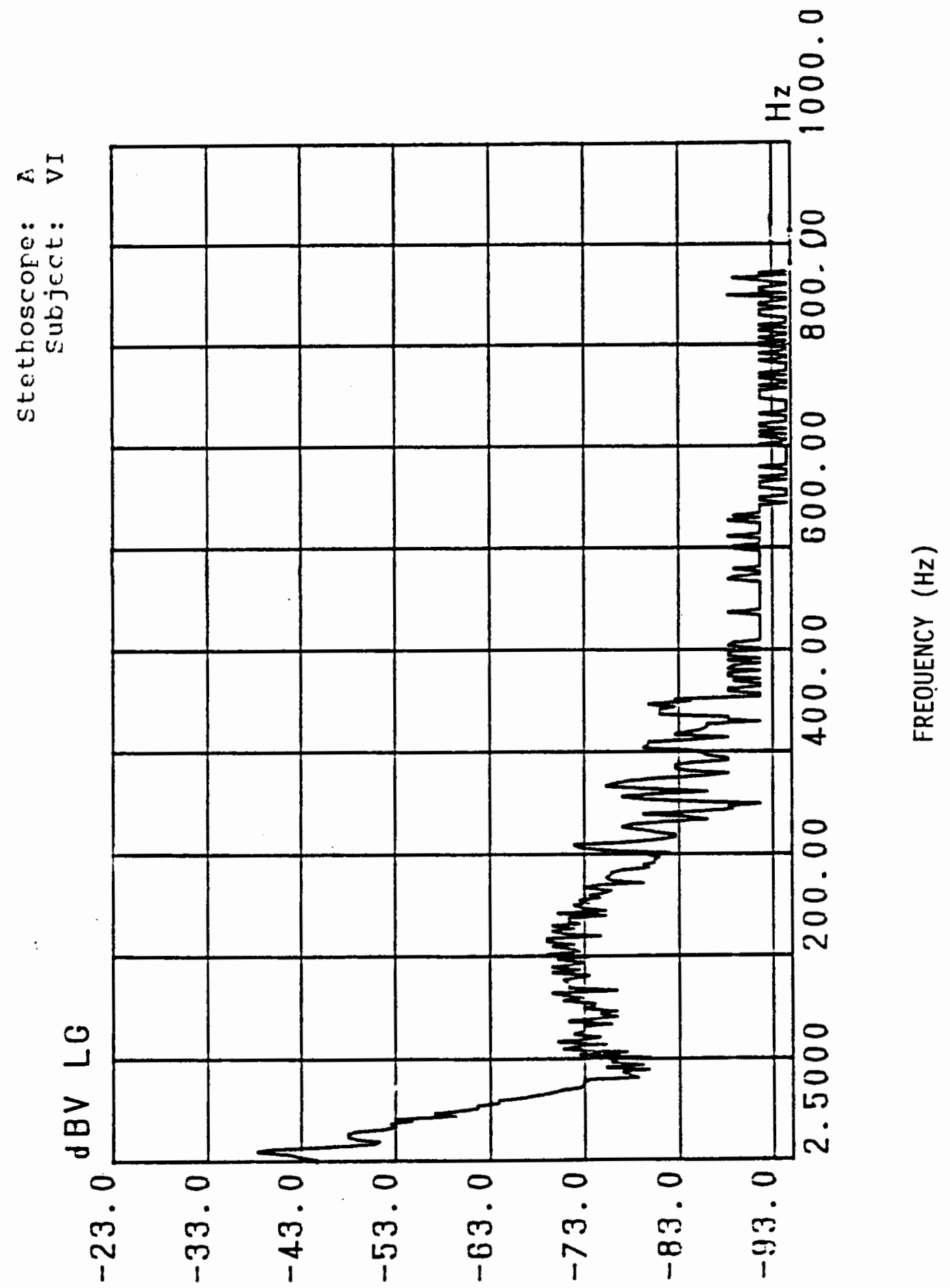

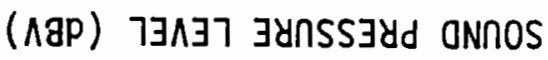




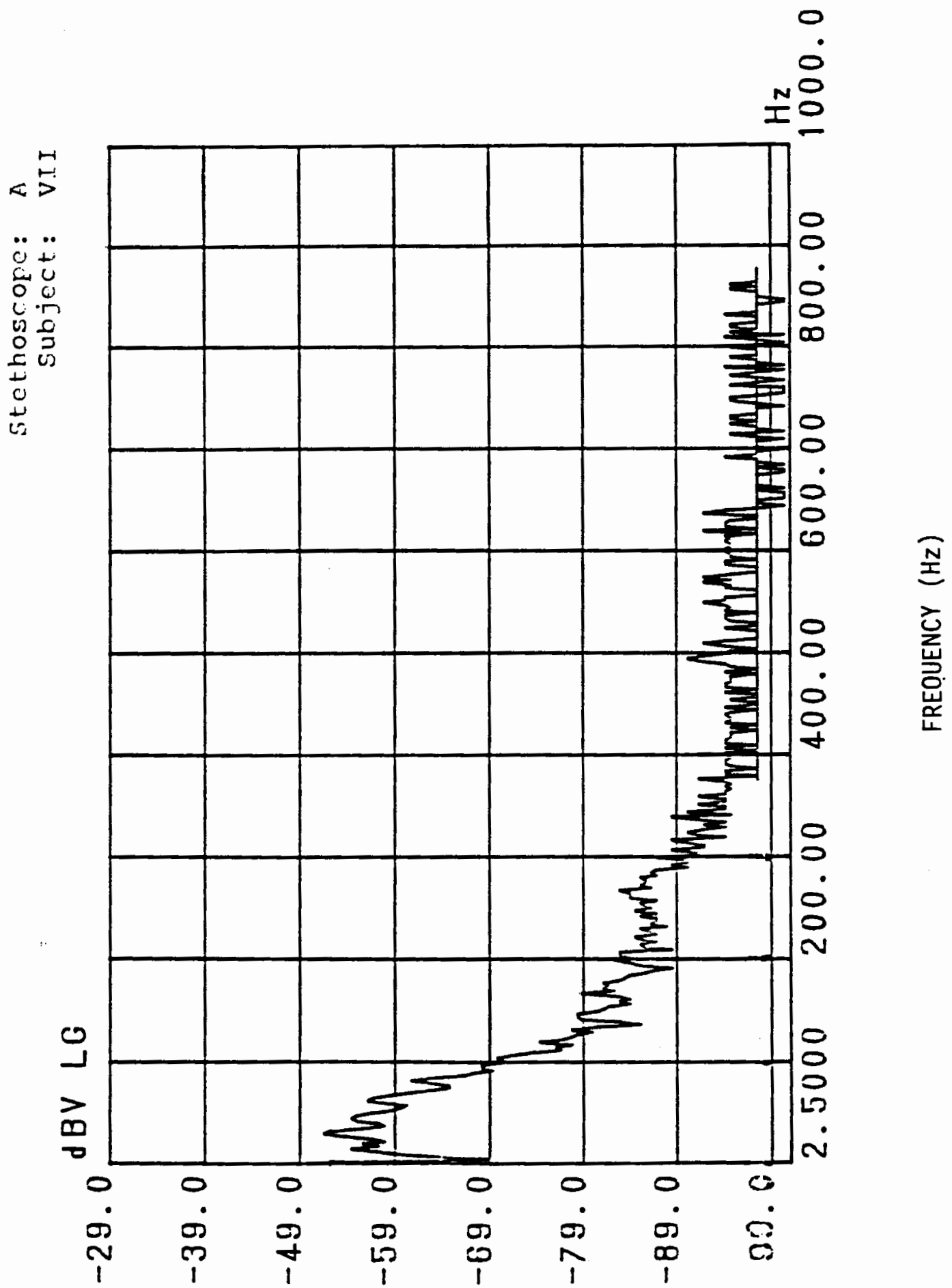

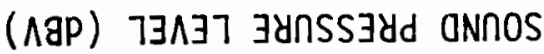




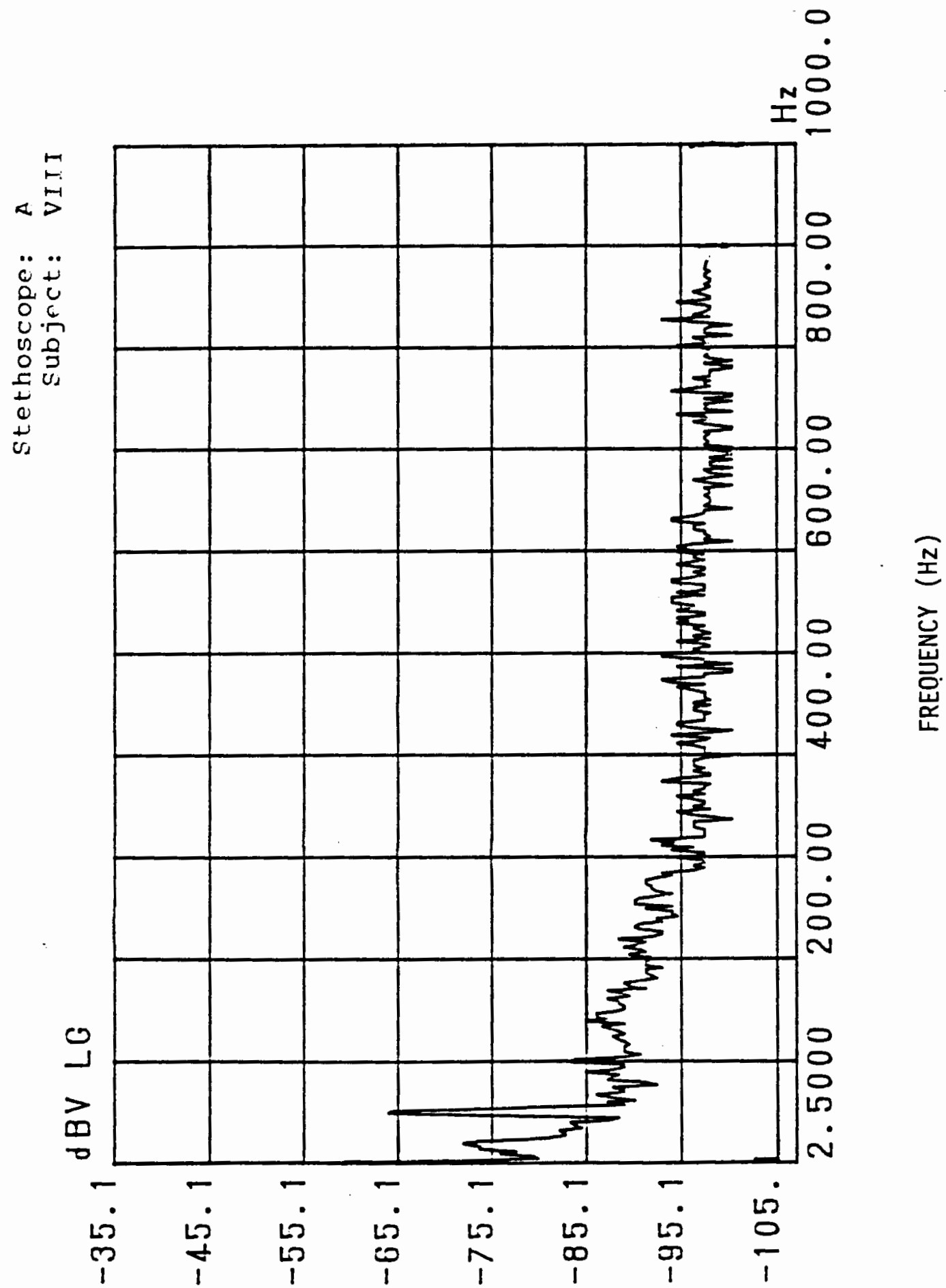

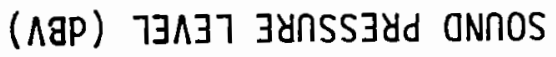




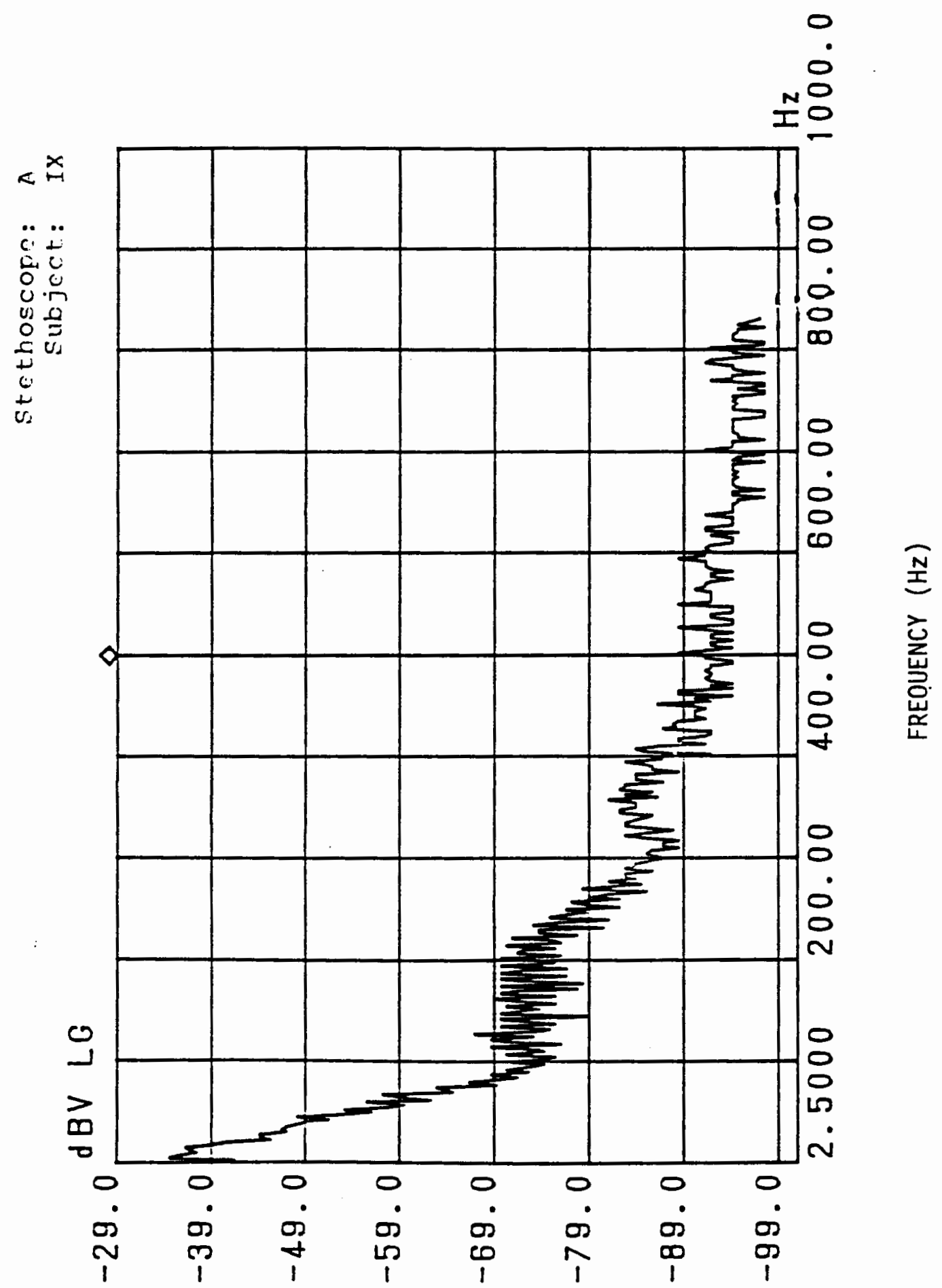

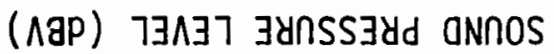




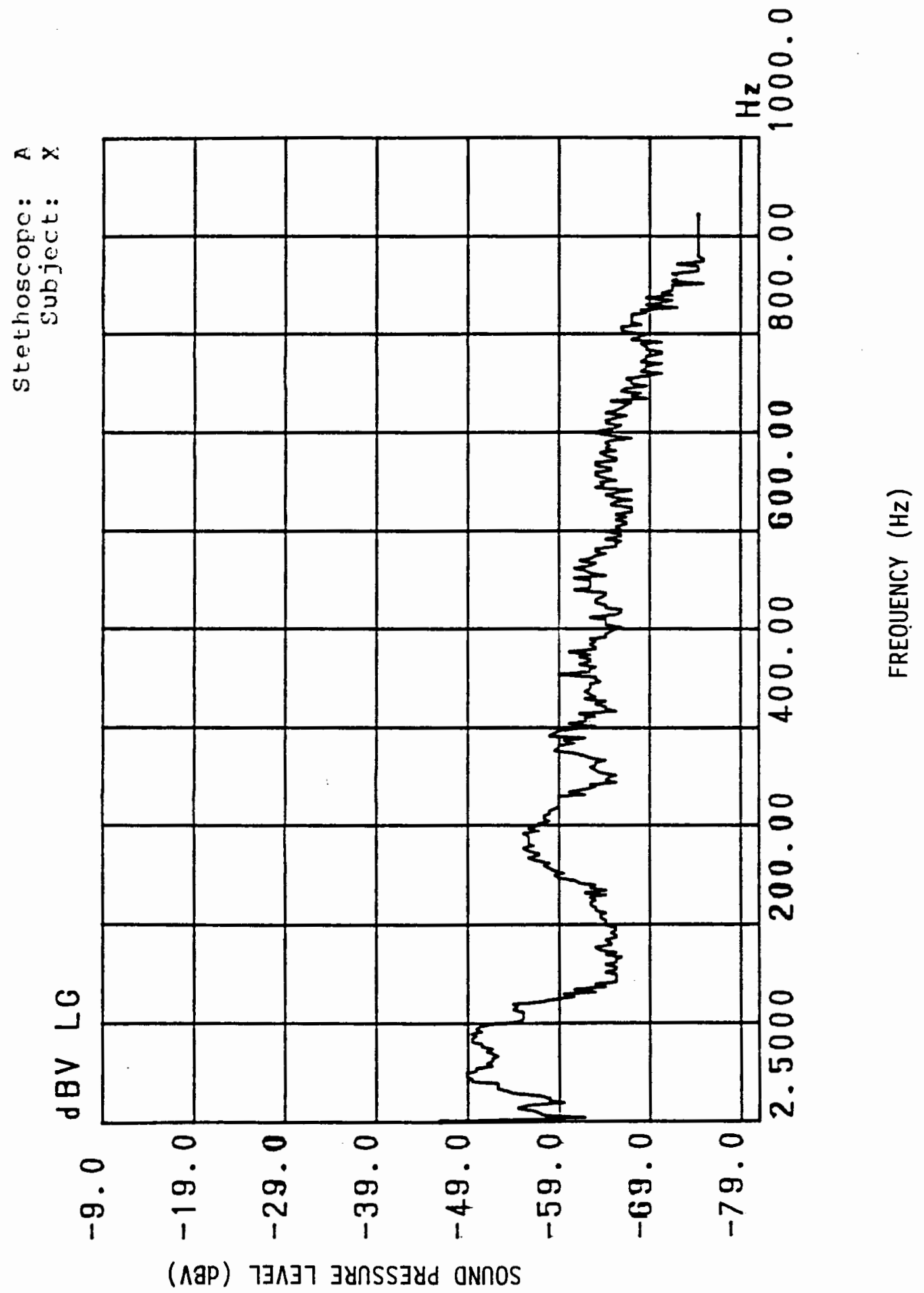




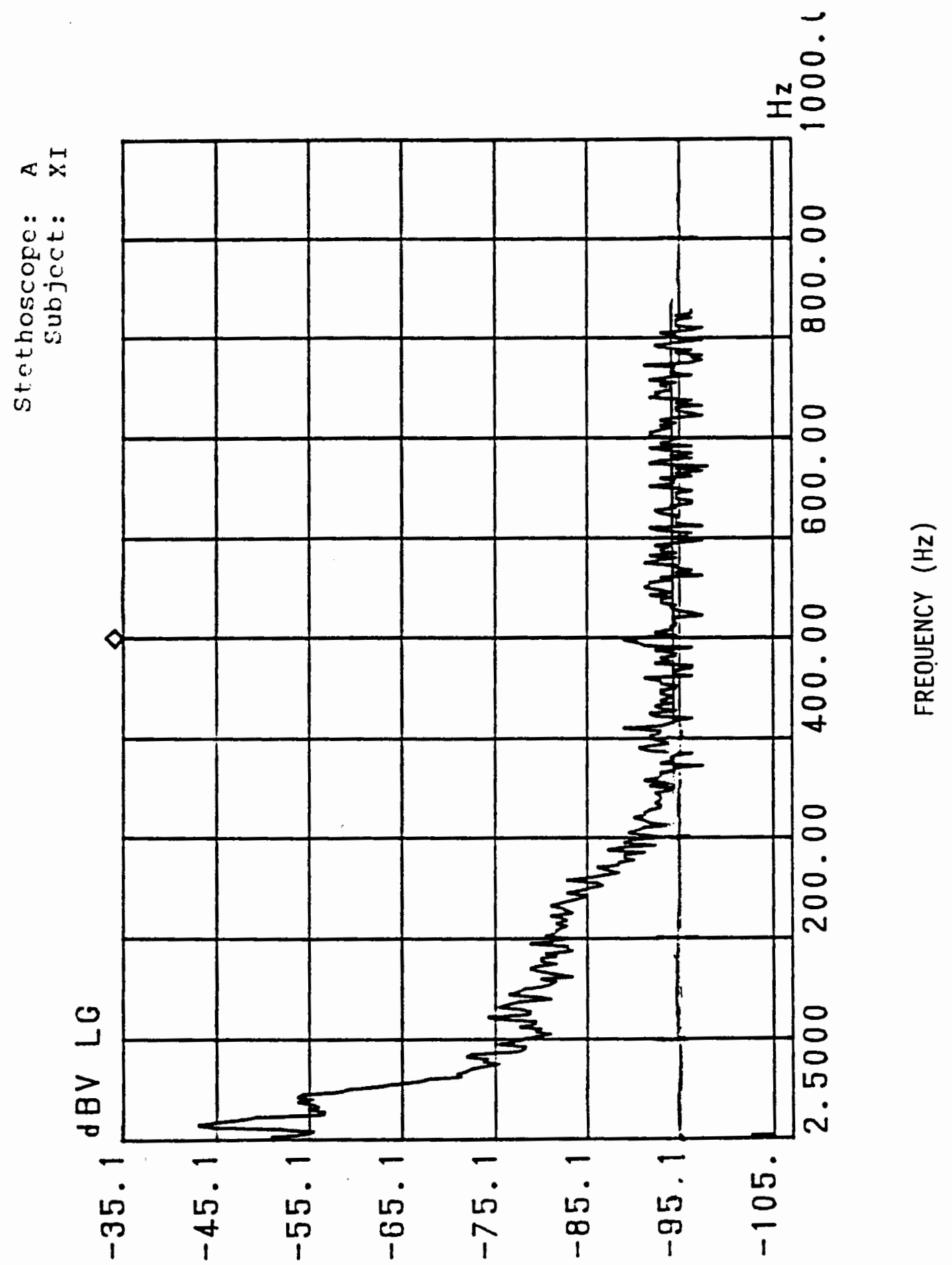

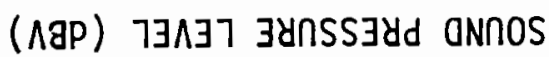




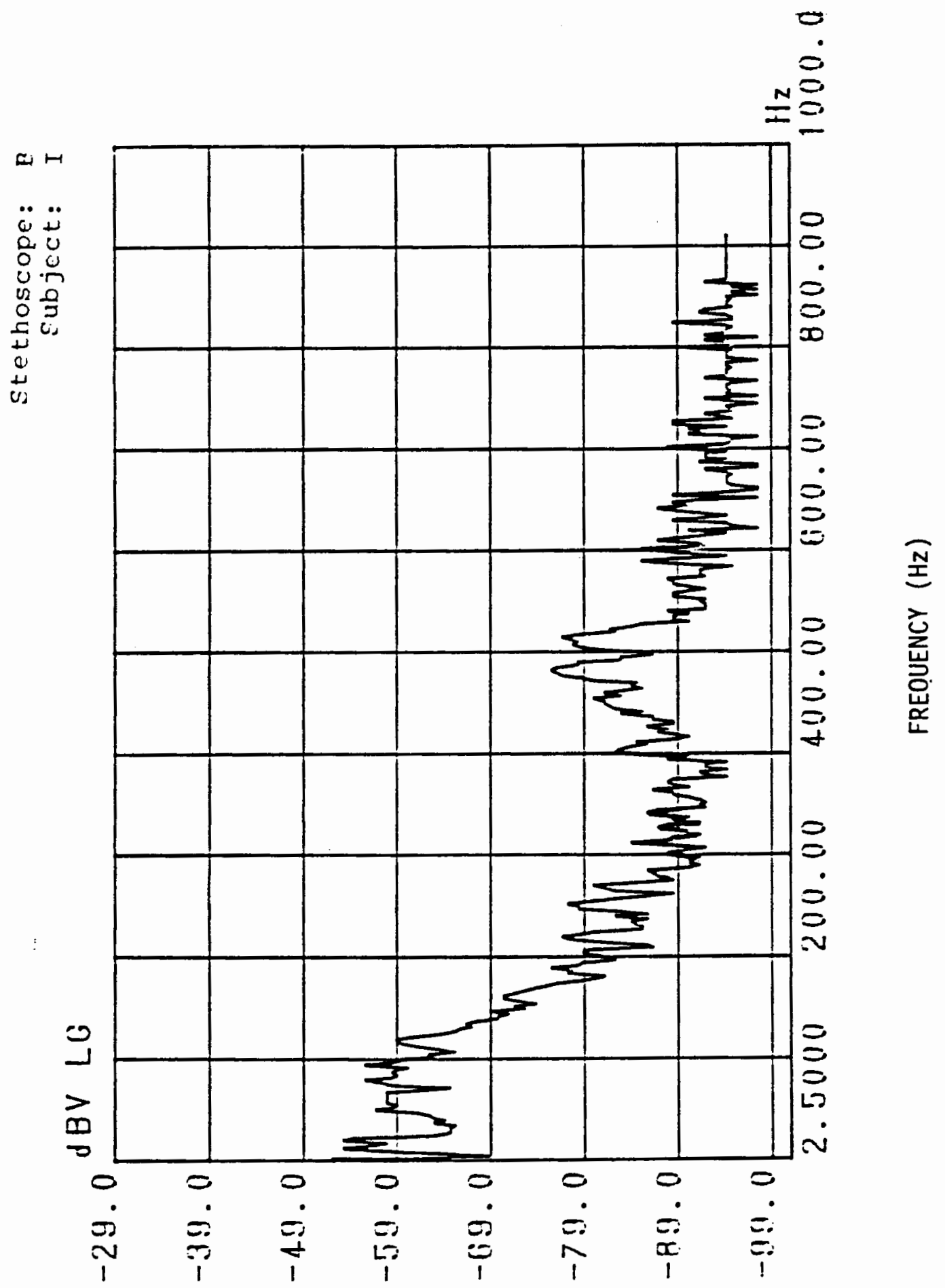

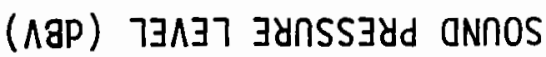




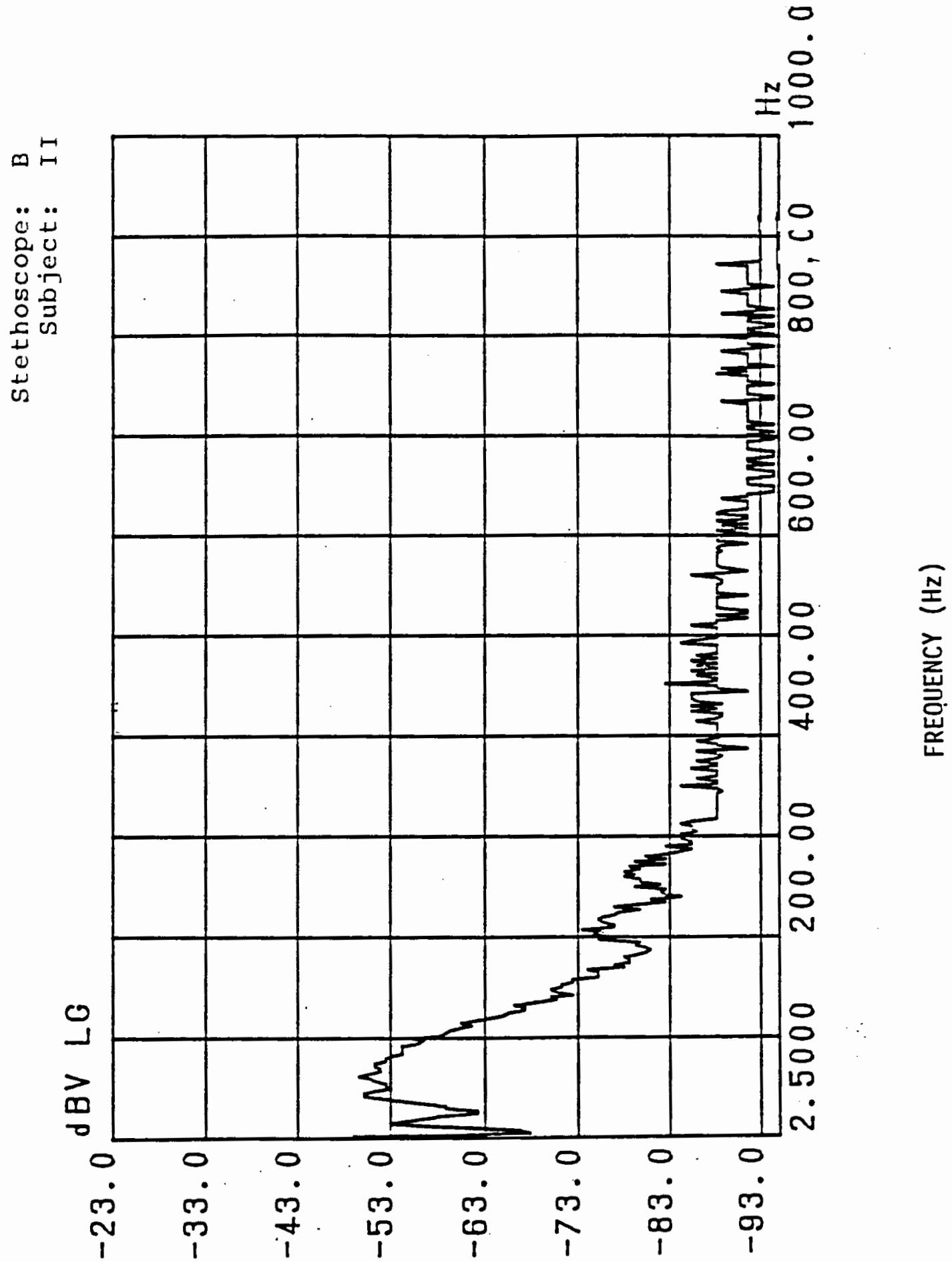

(^ар) 73^37 3yns5zydd onnOs 


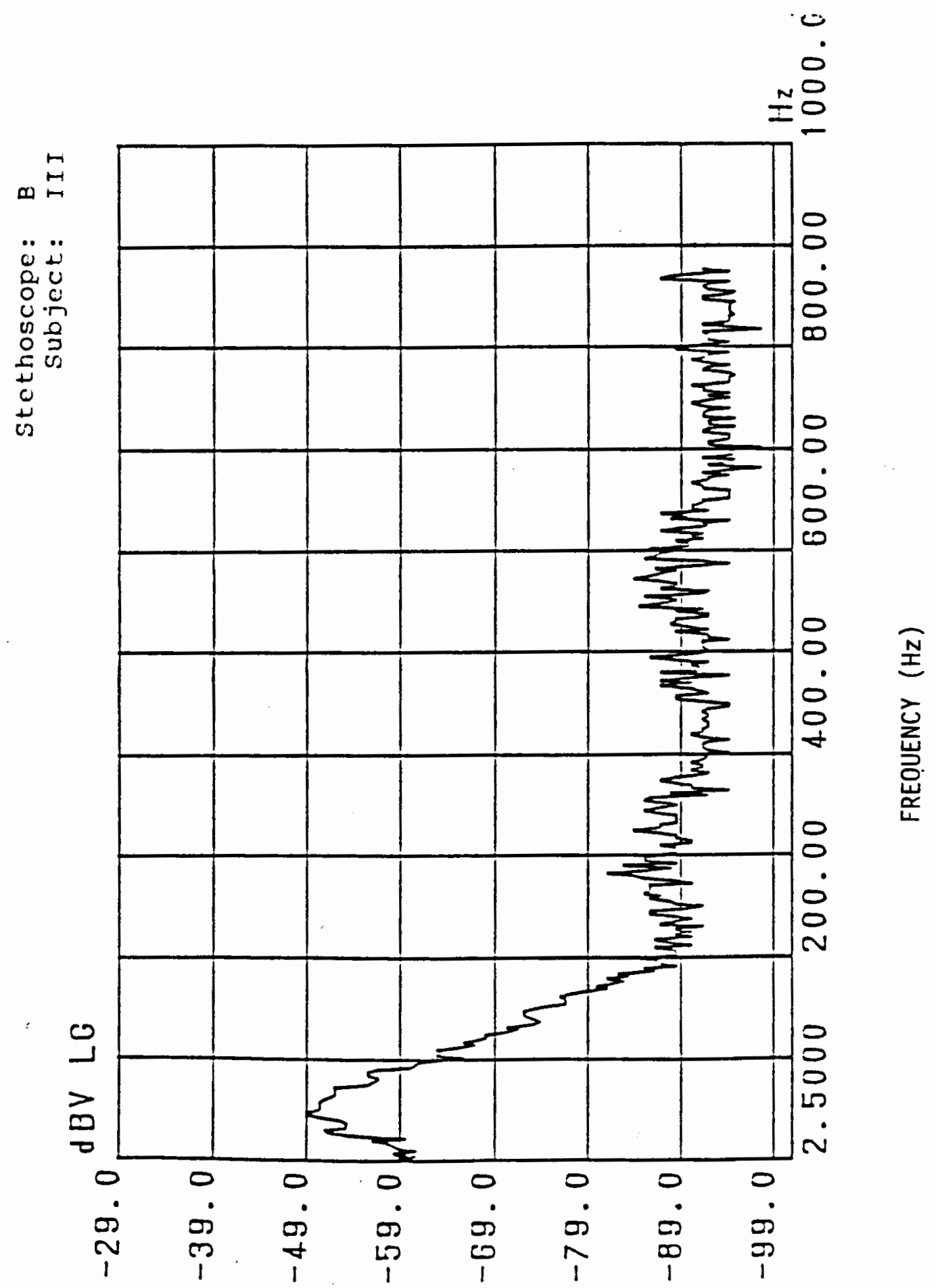




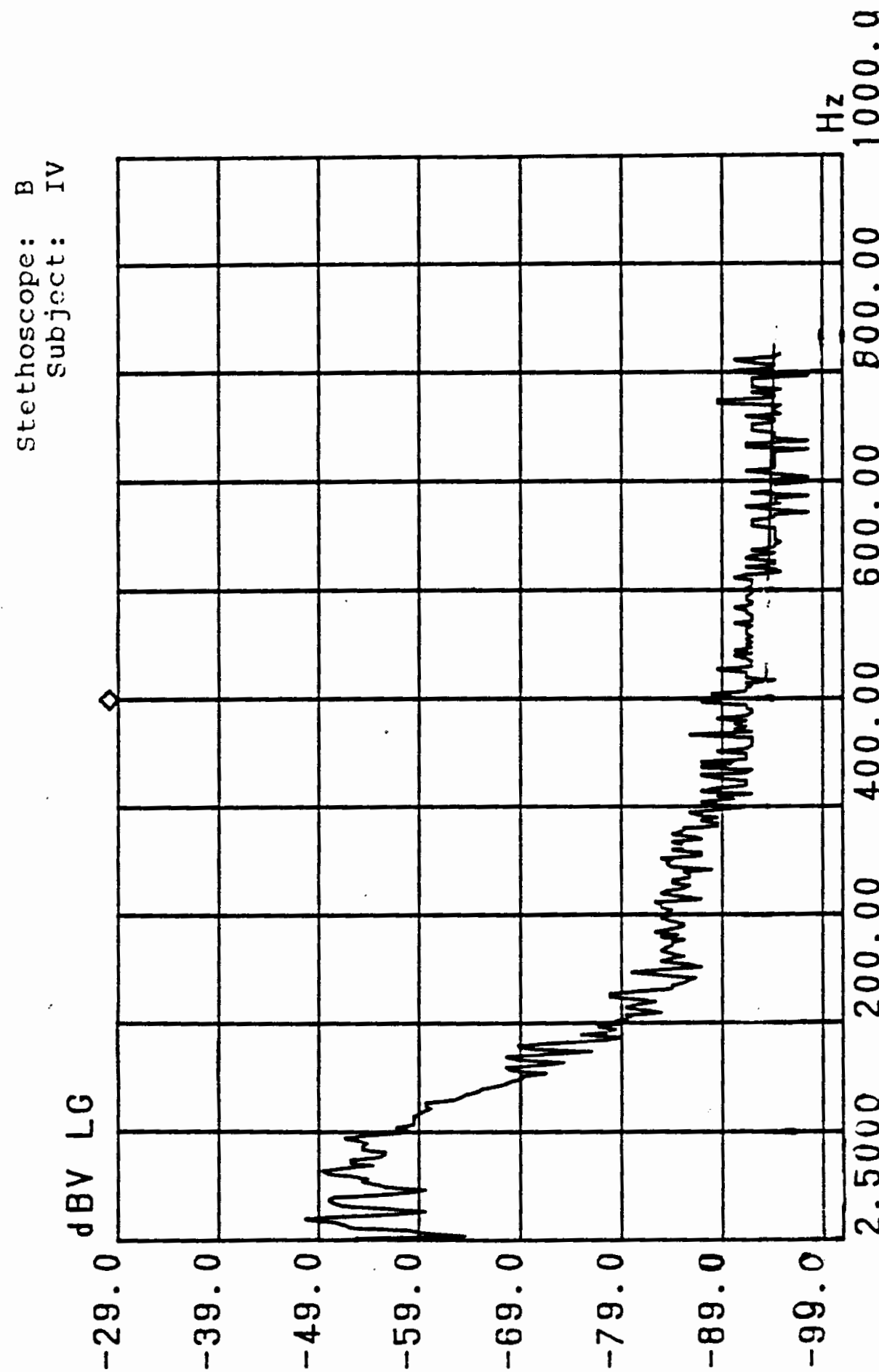

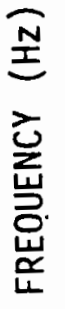

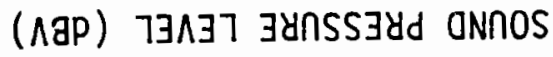




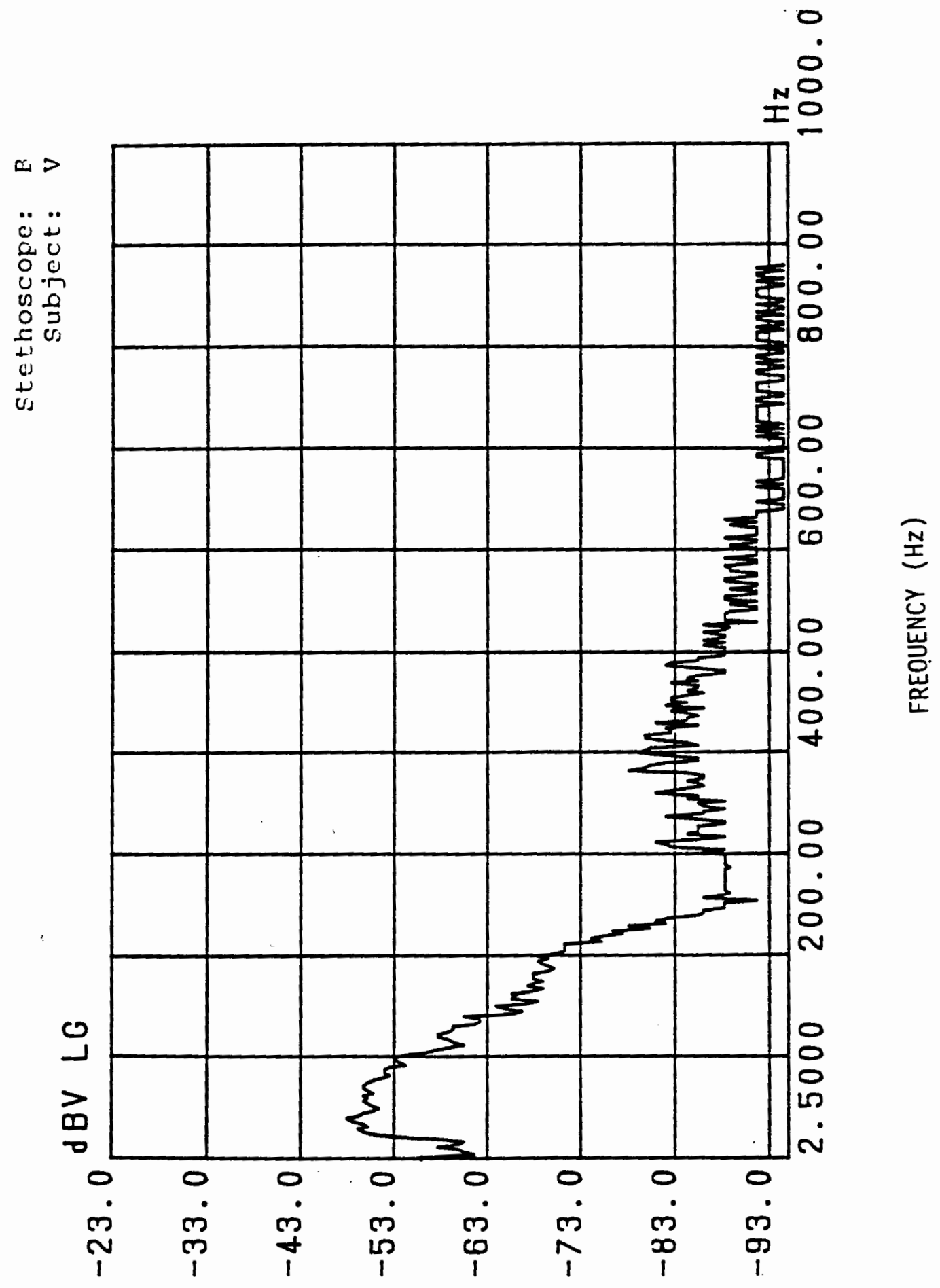

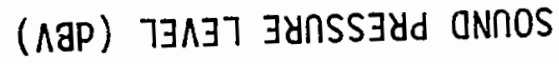




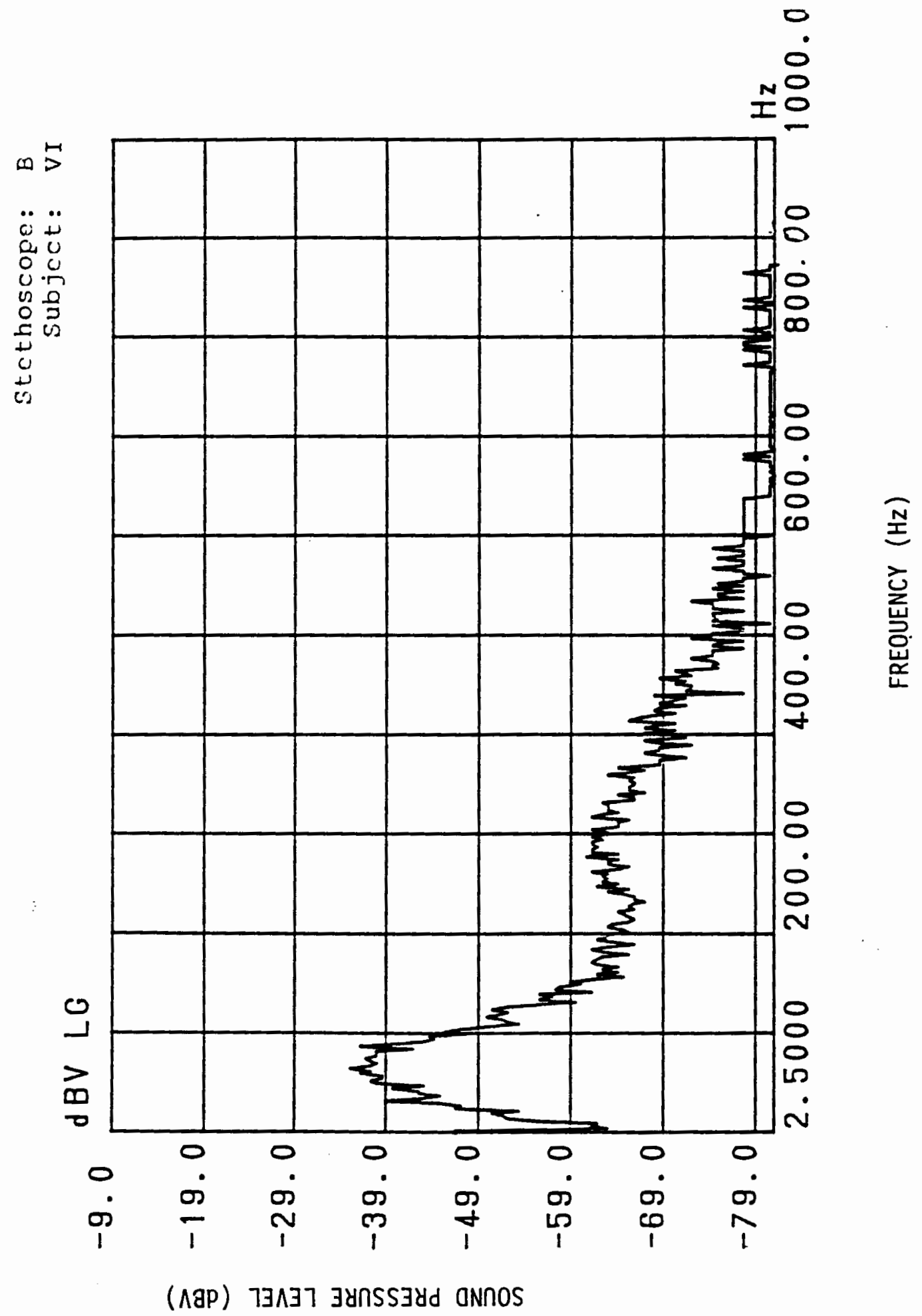




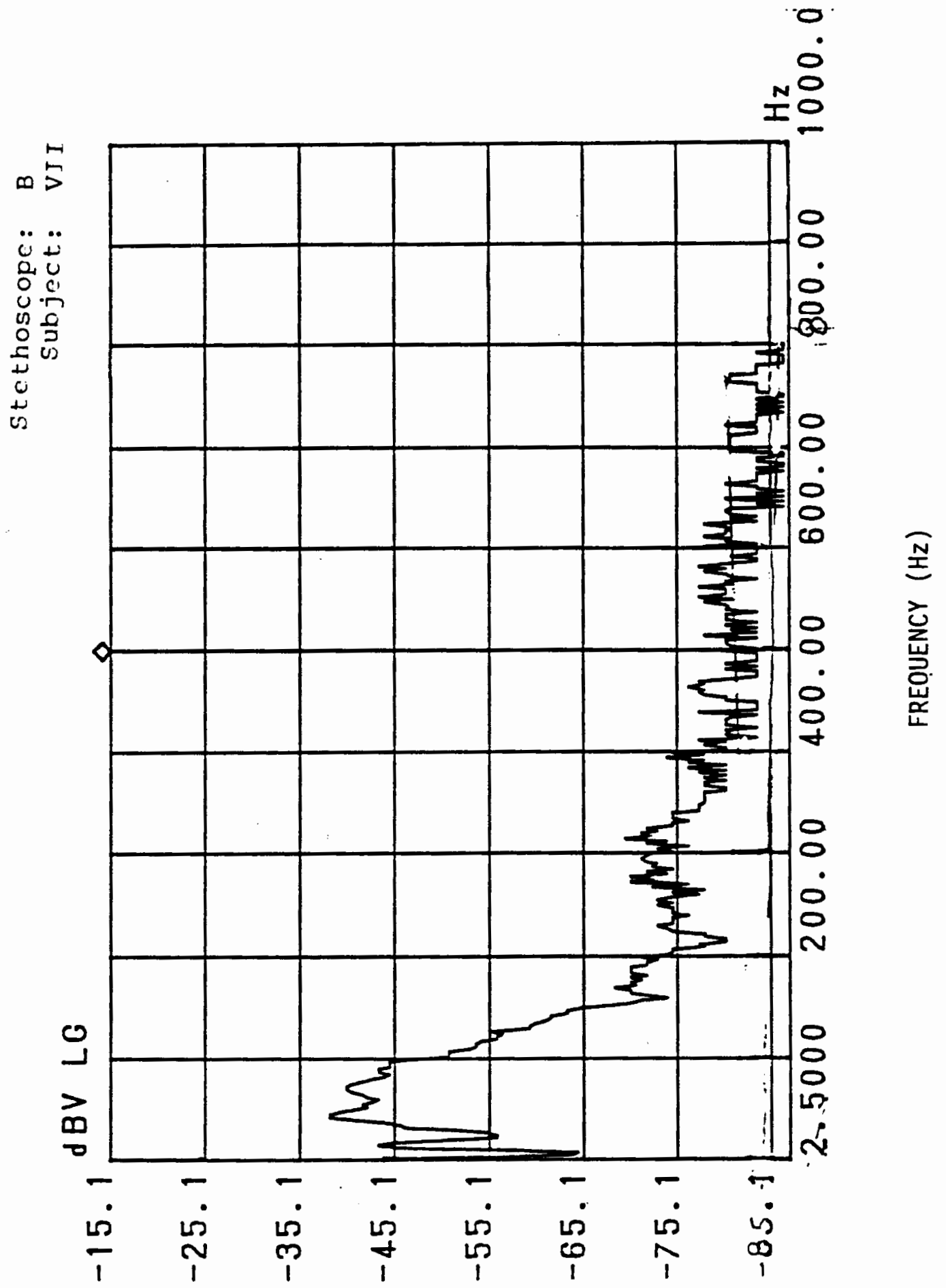

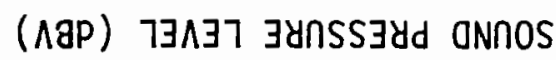




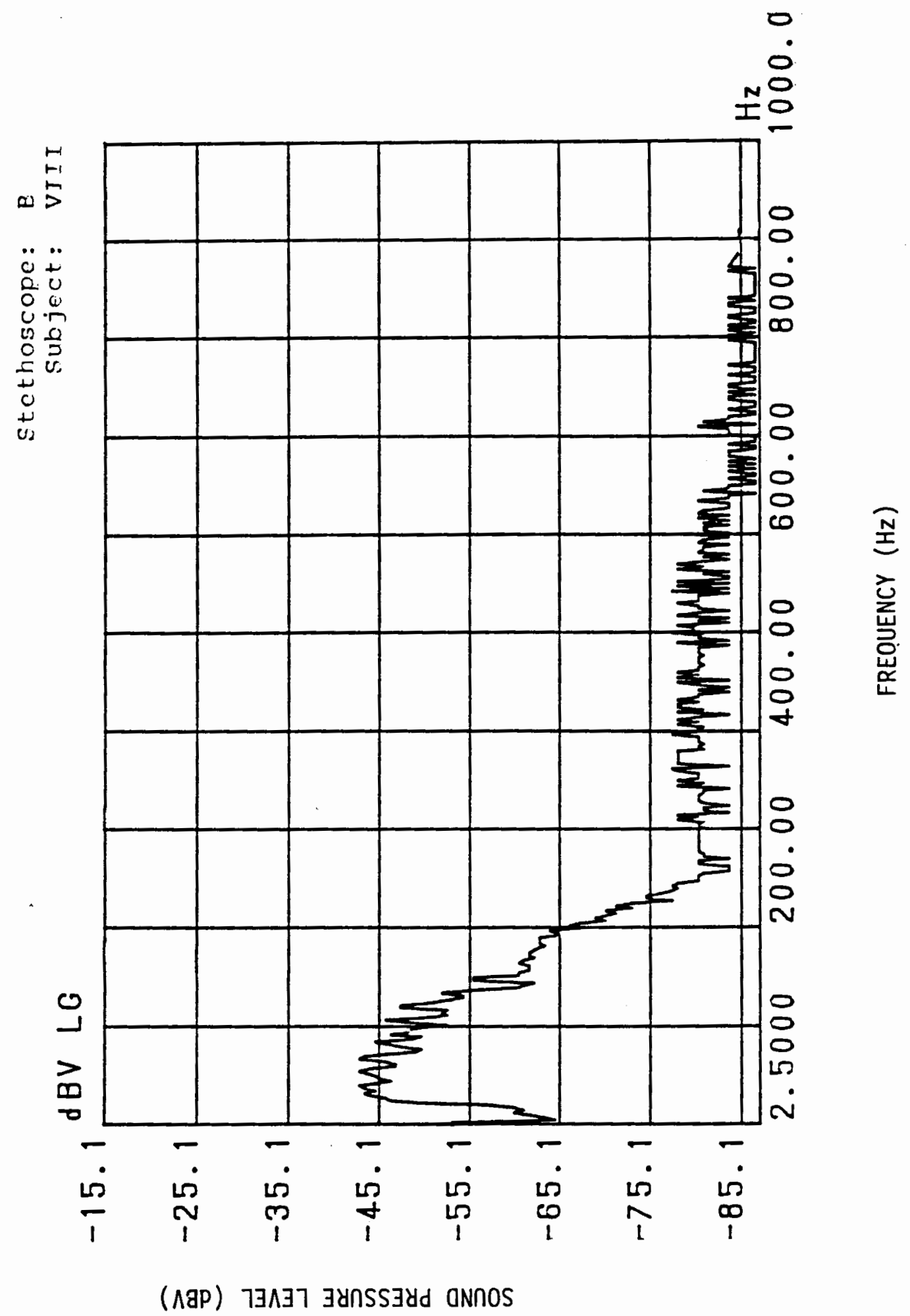




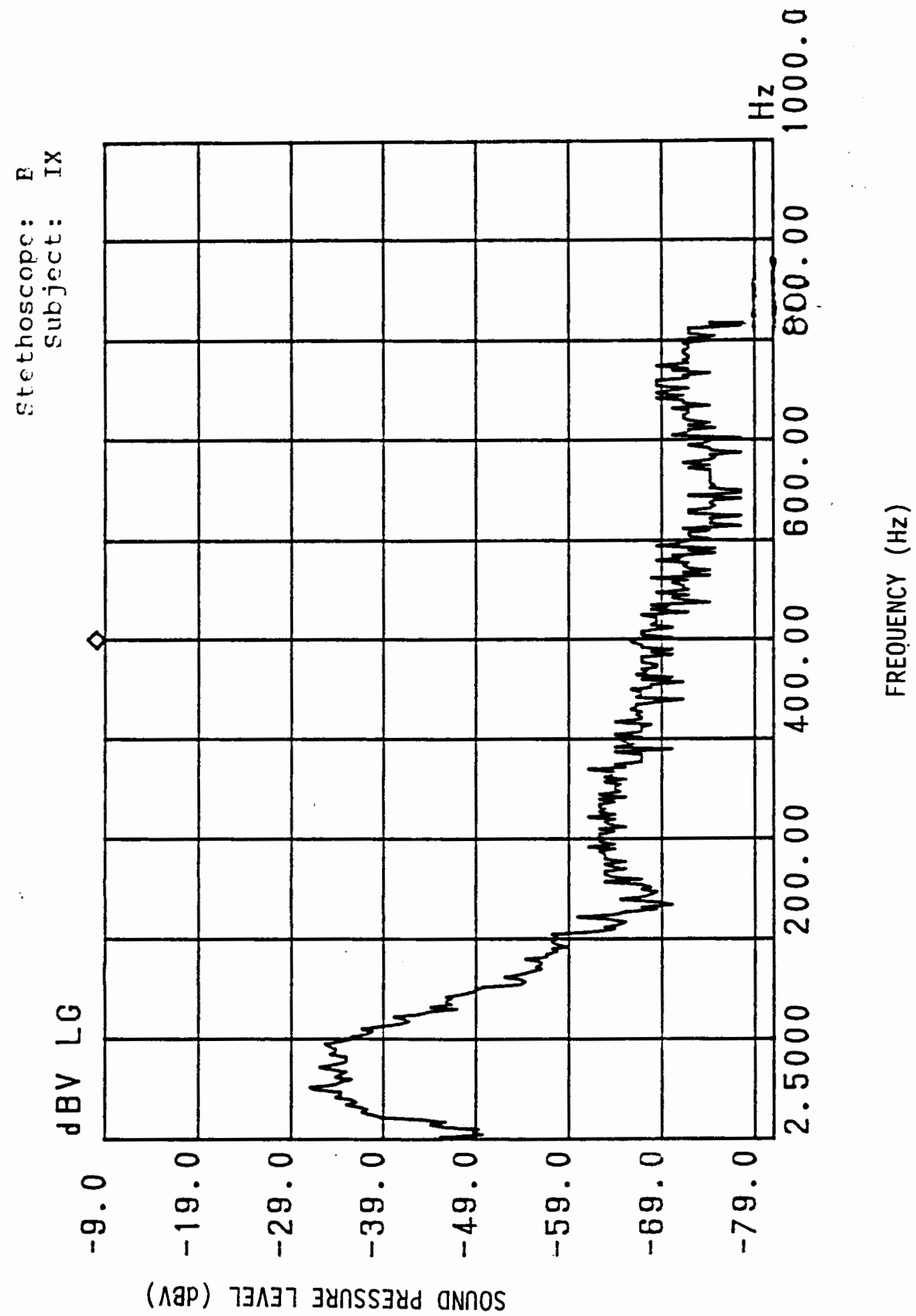




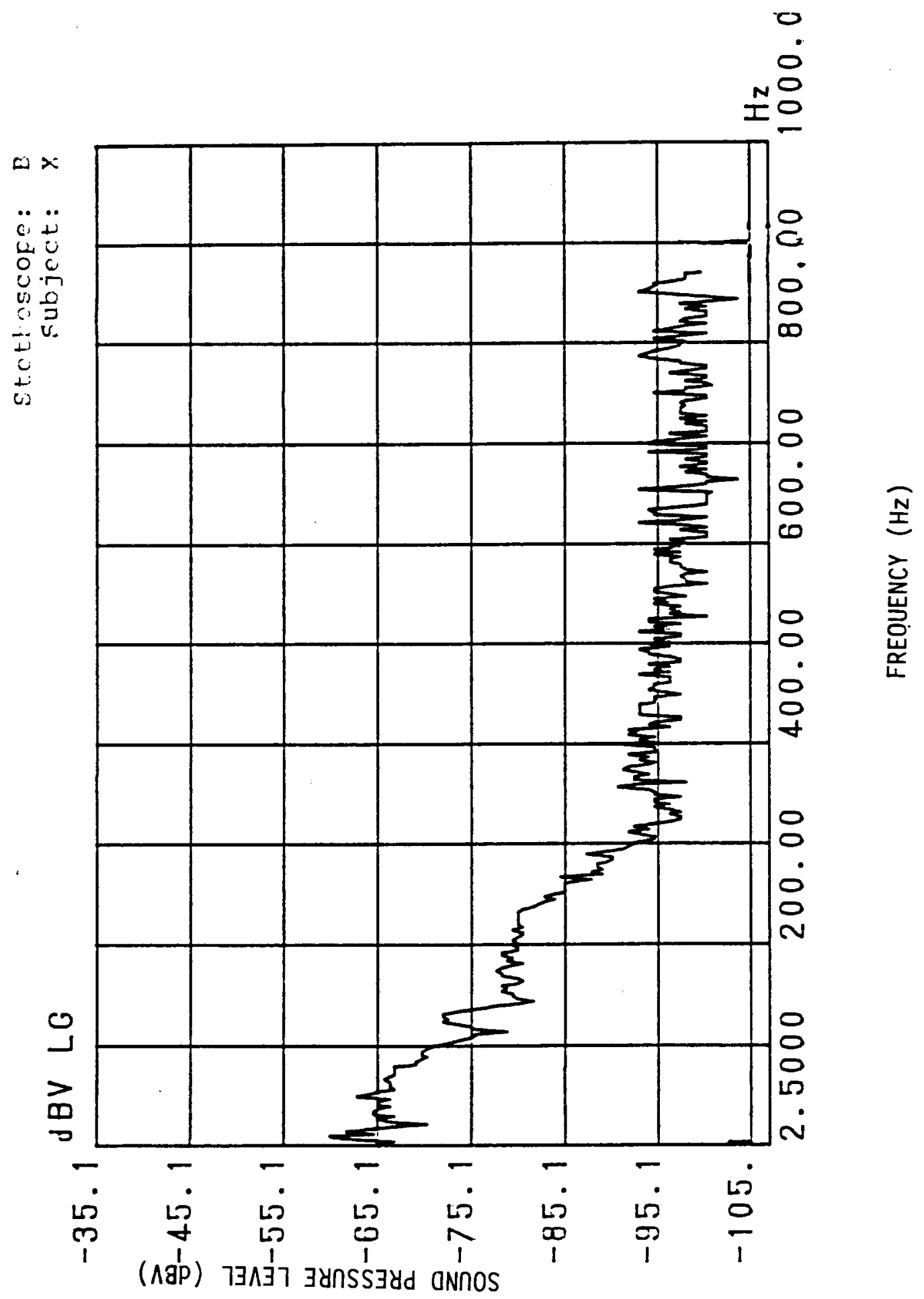




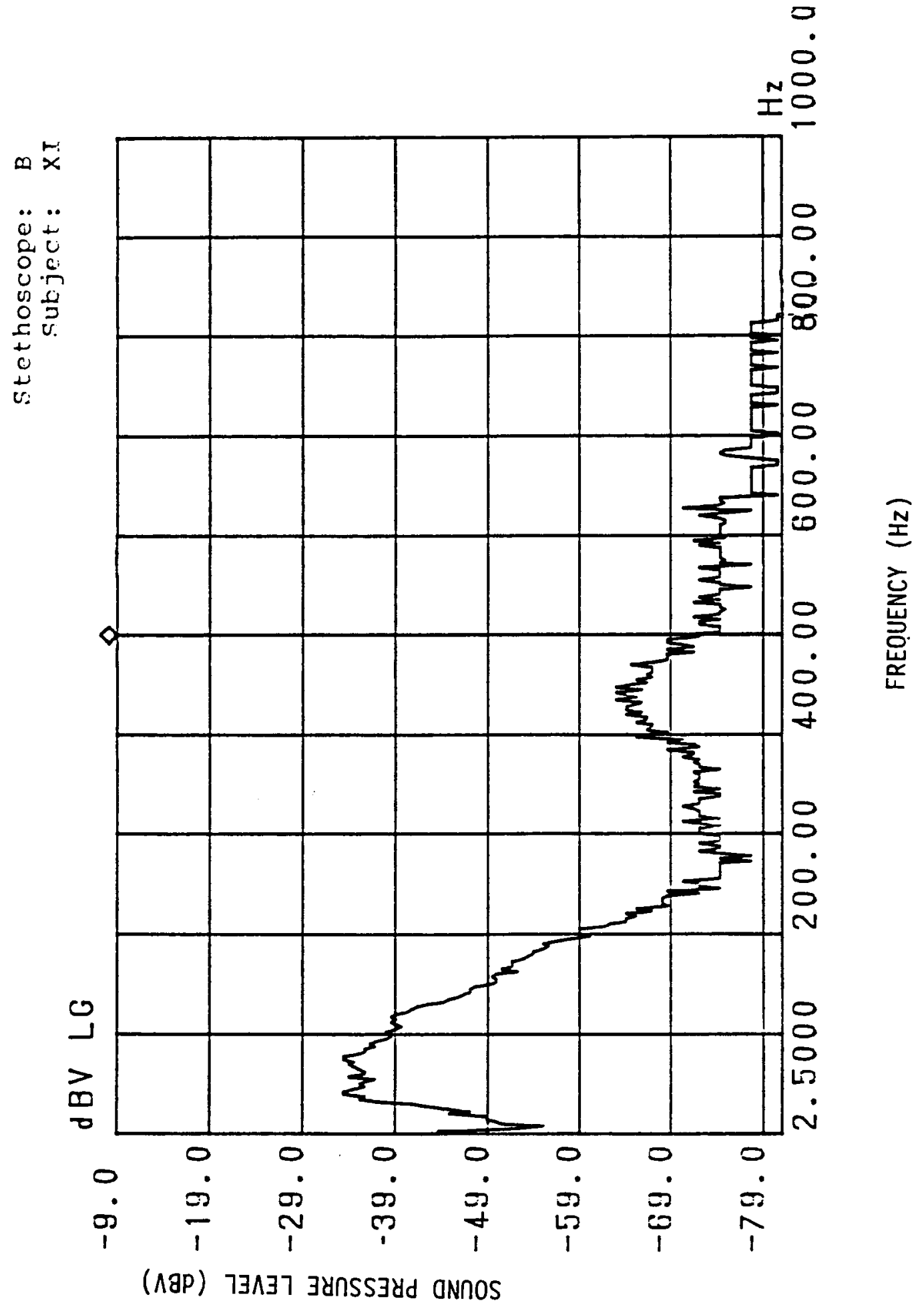




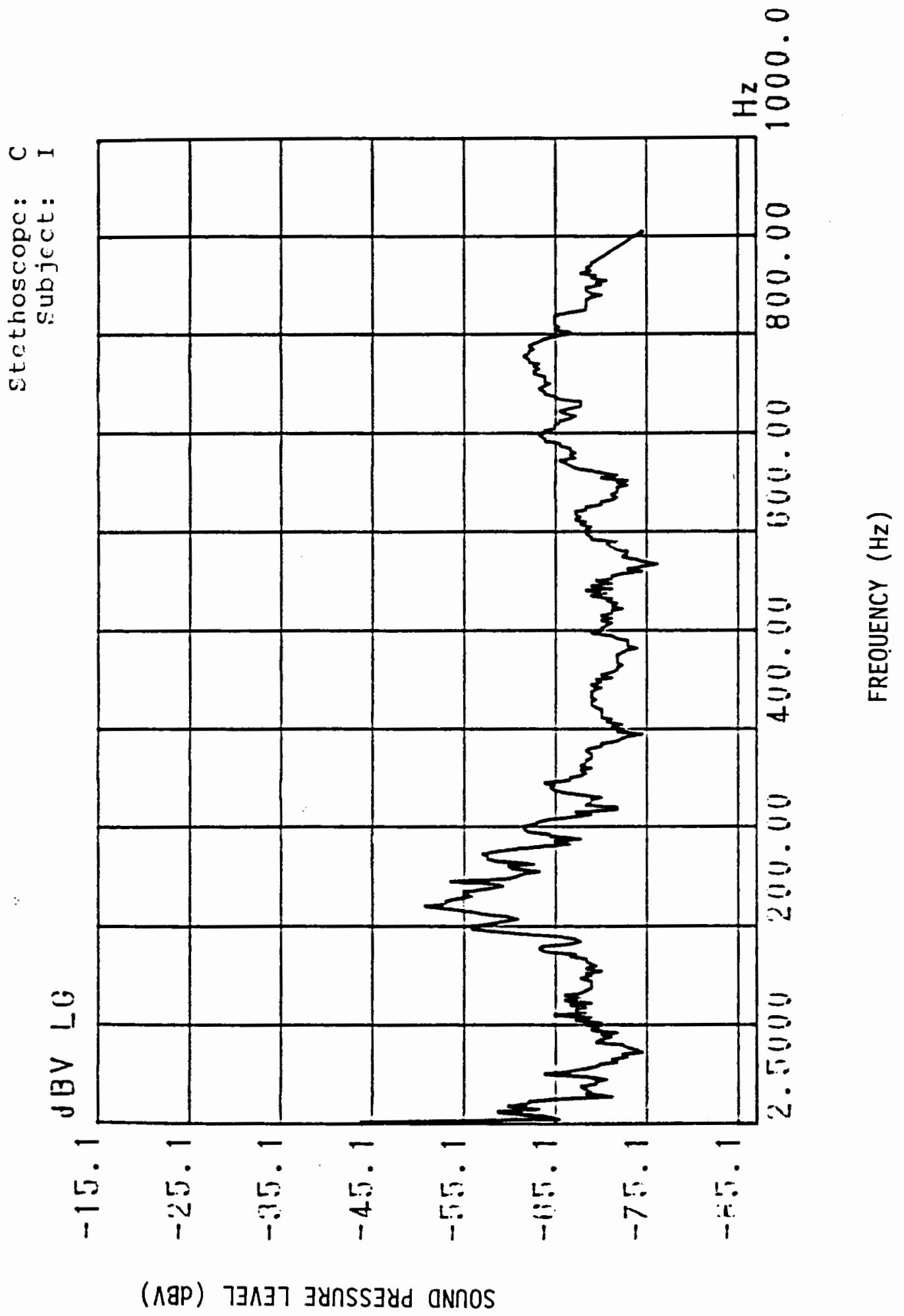




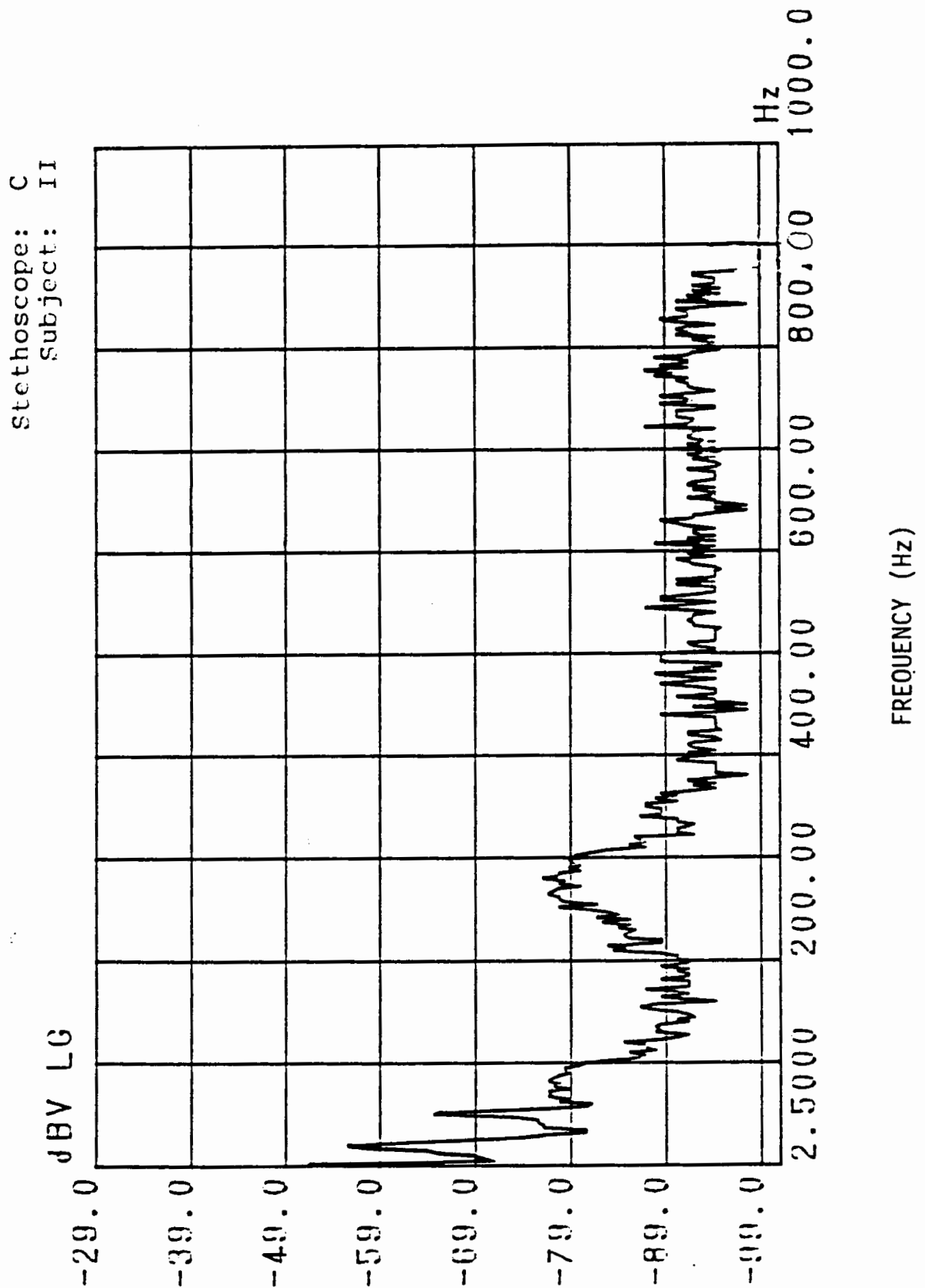

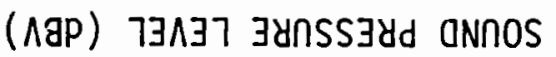




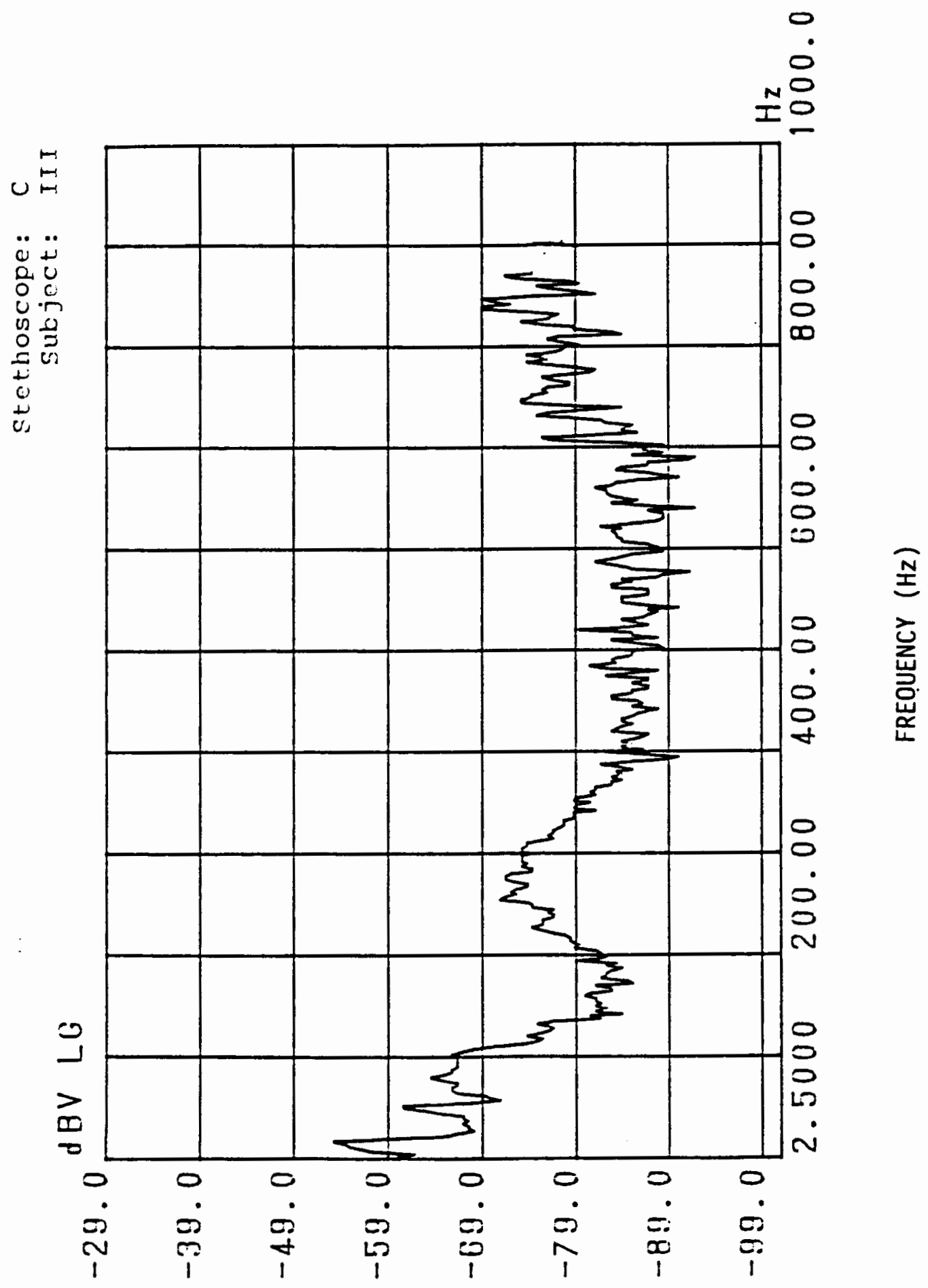

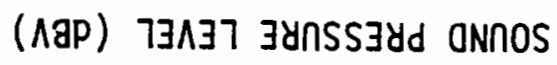




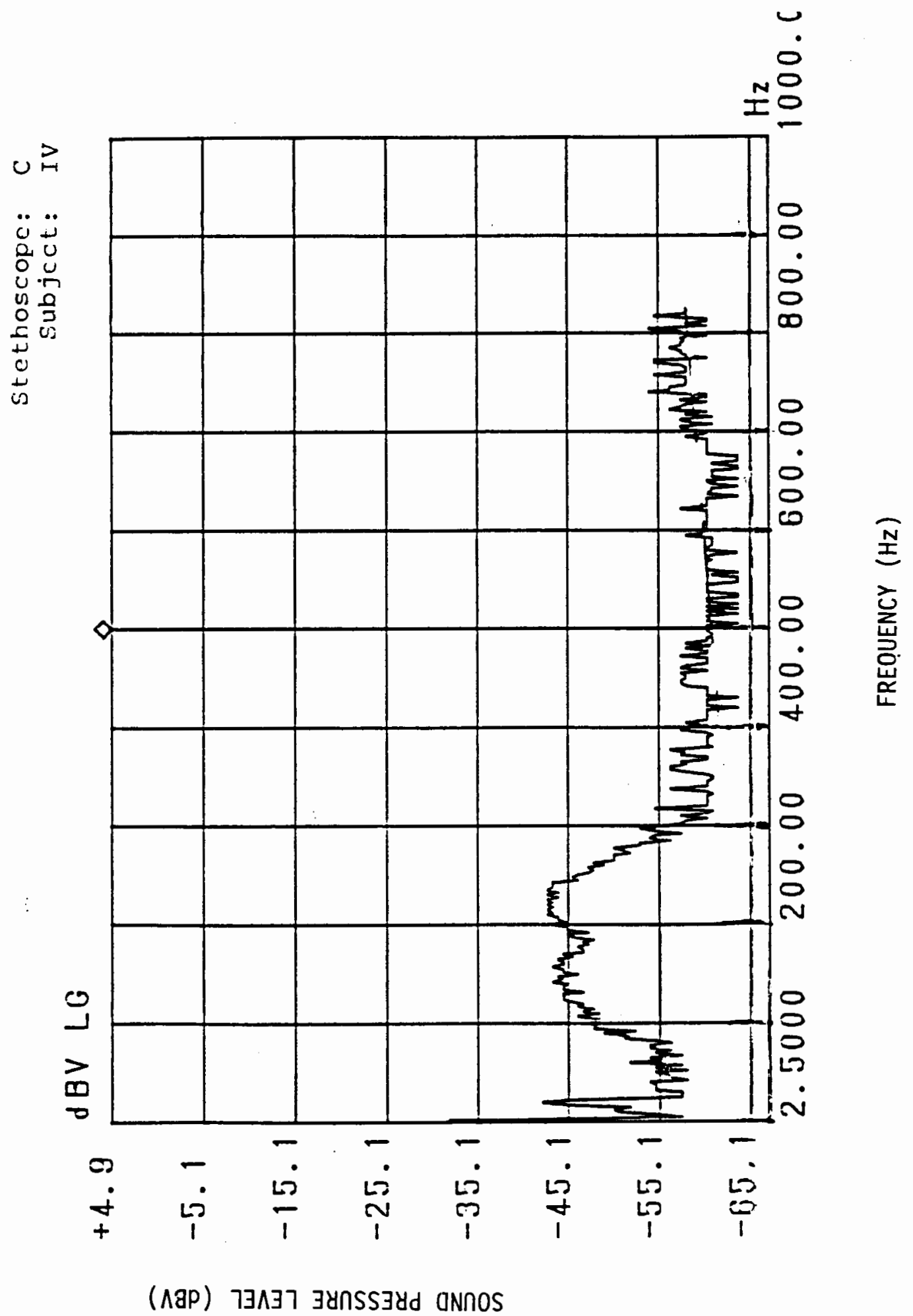




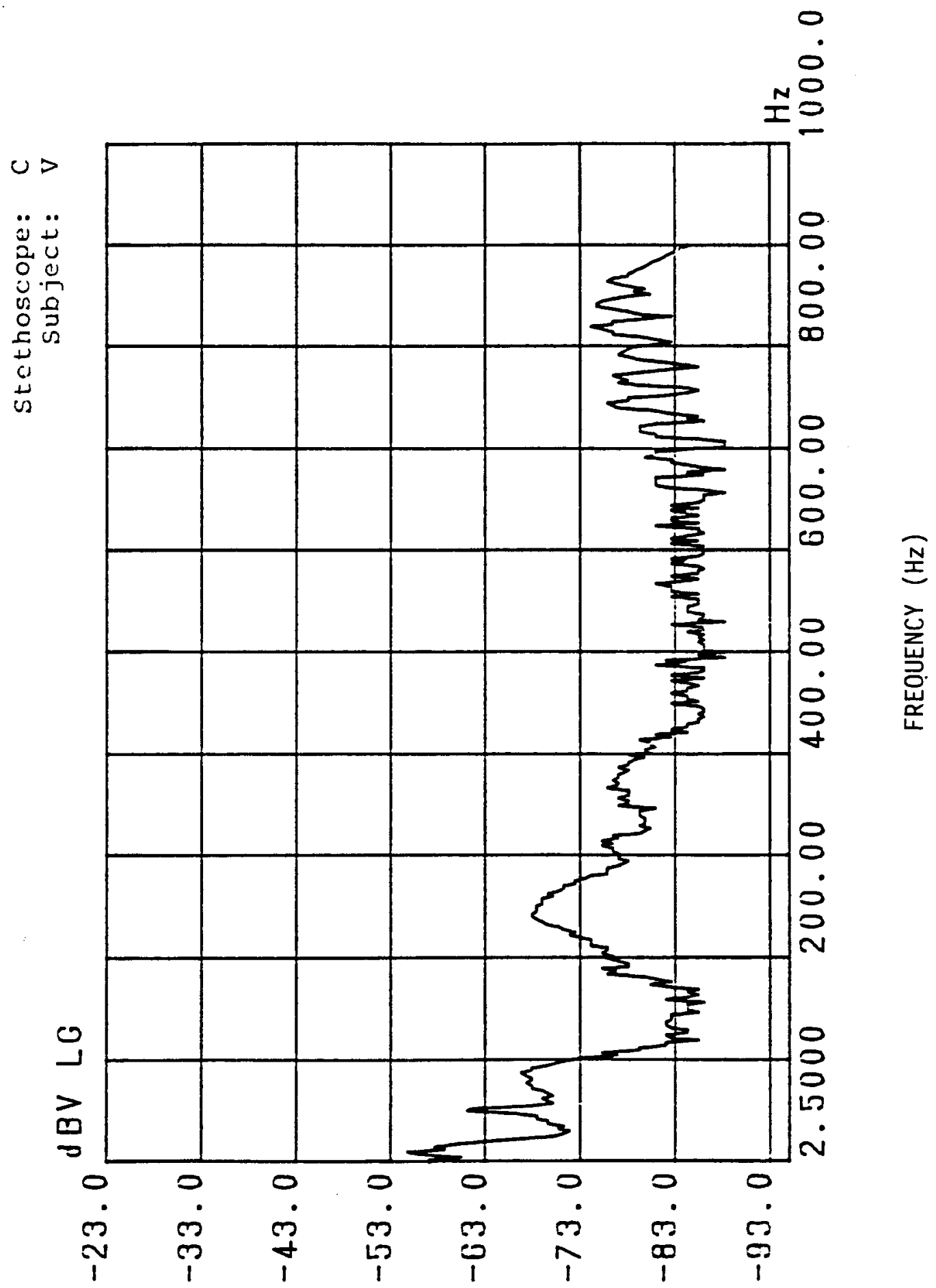

( 


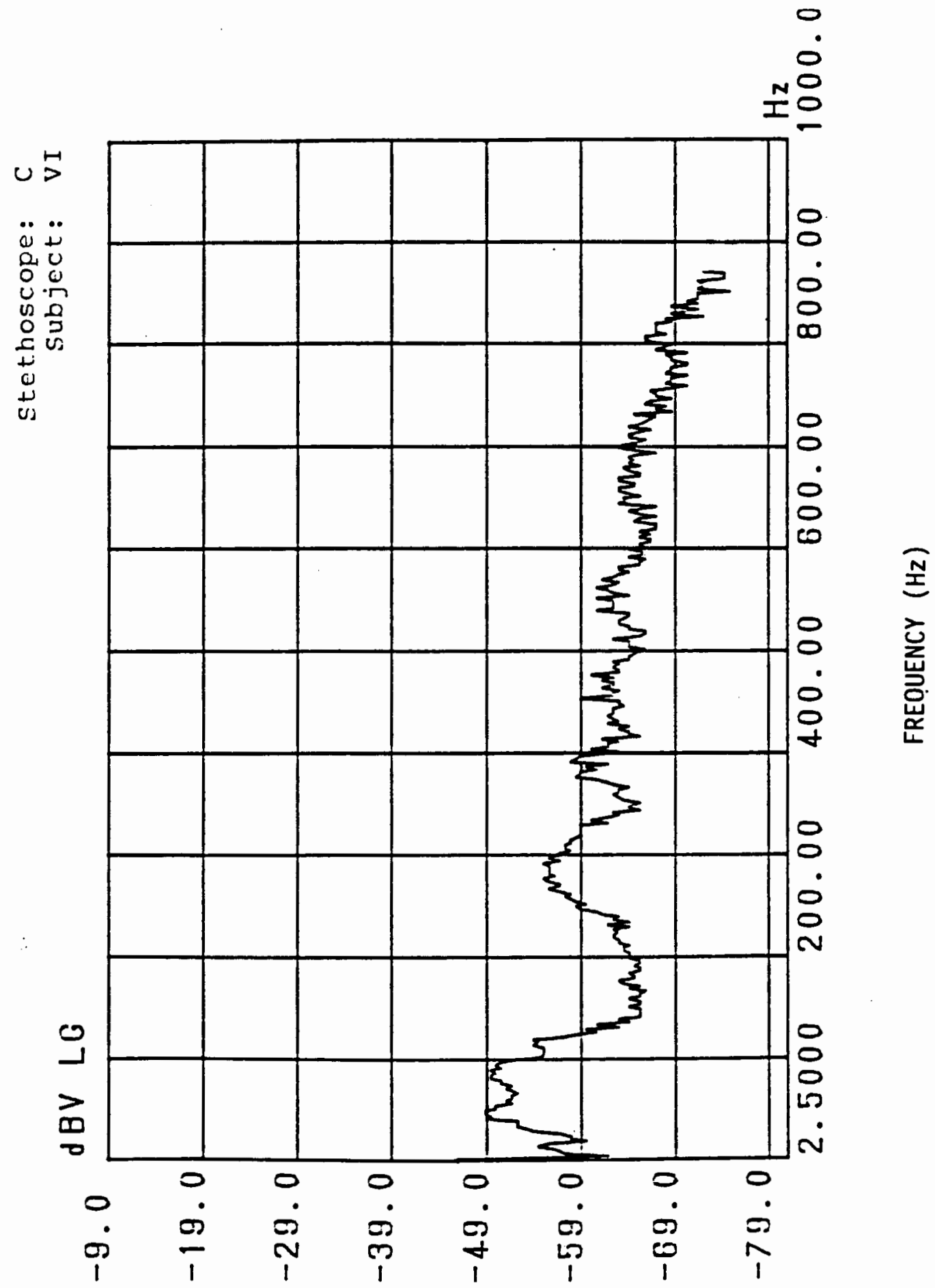

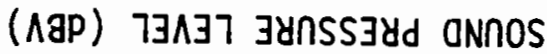




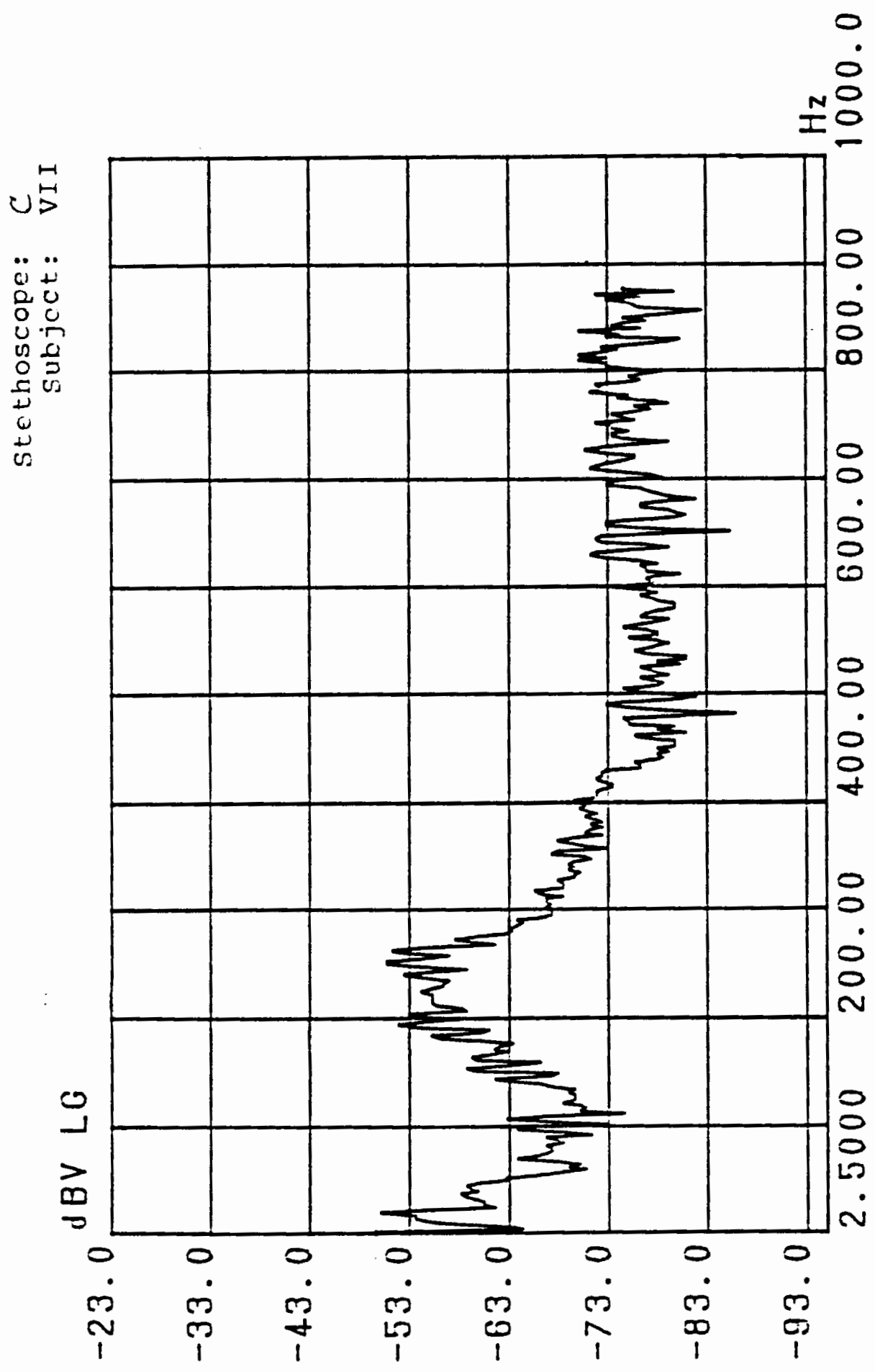

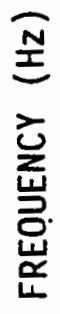

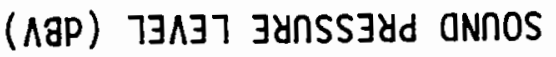




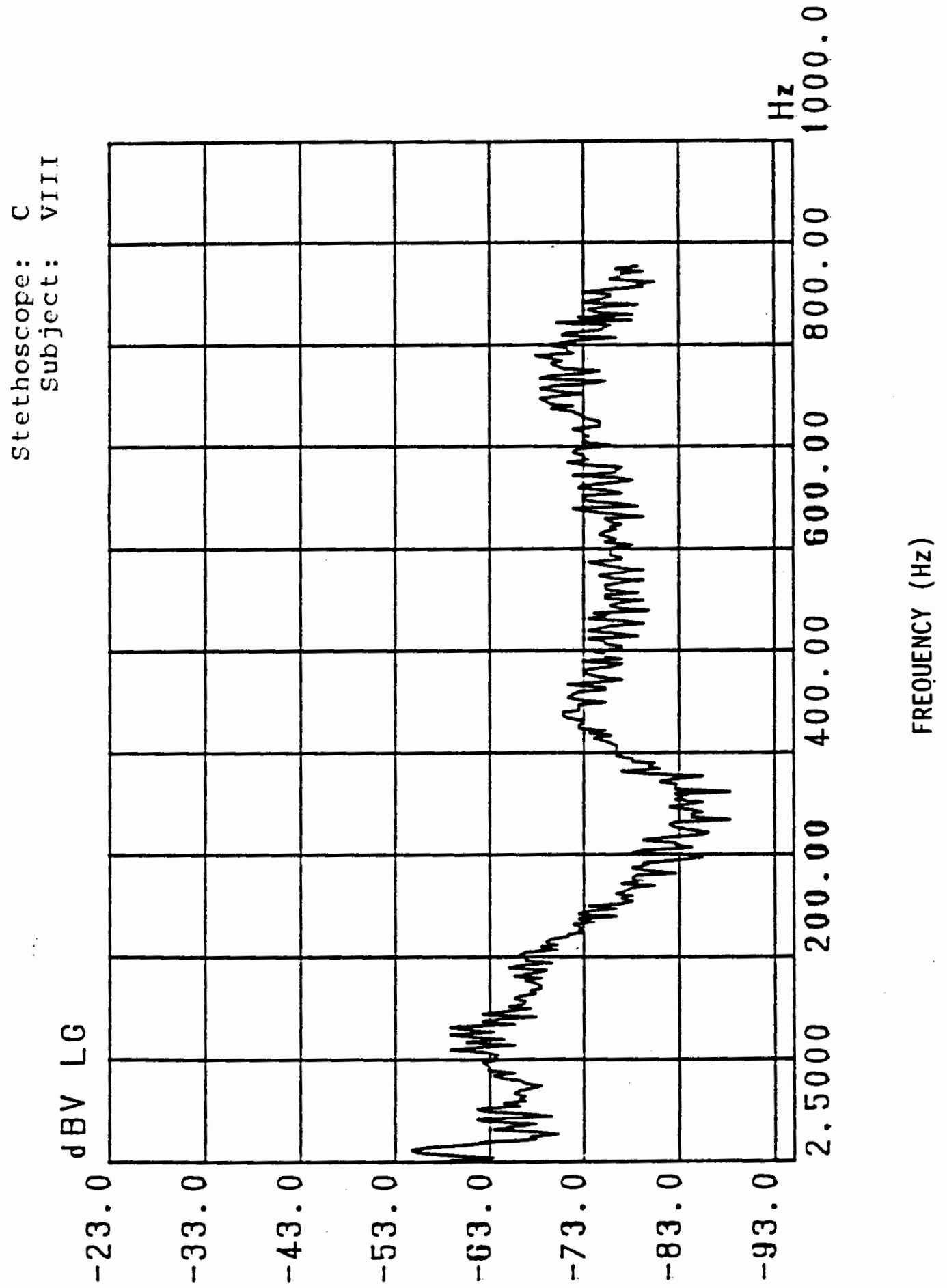

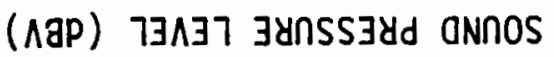




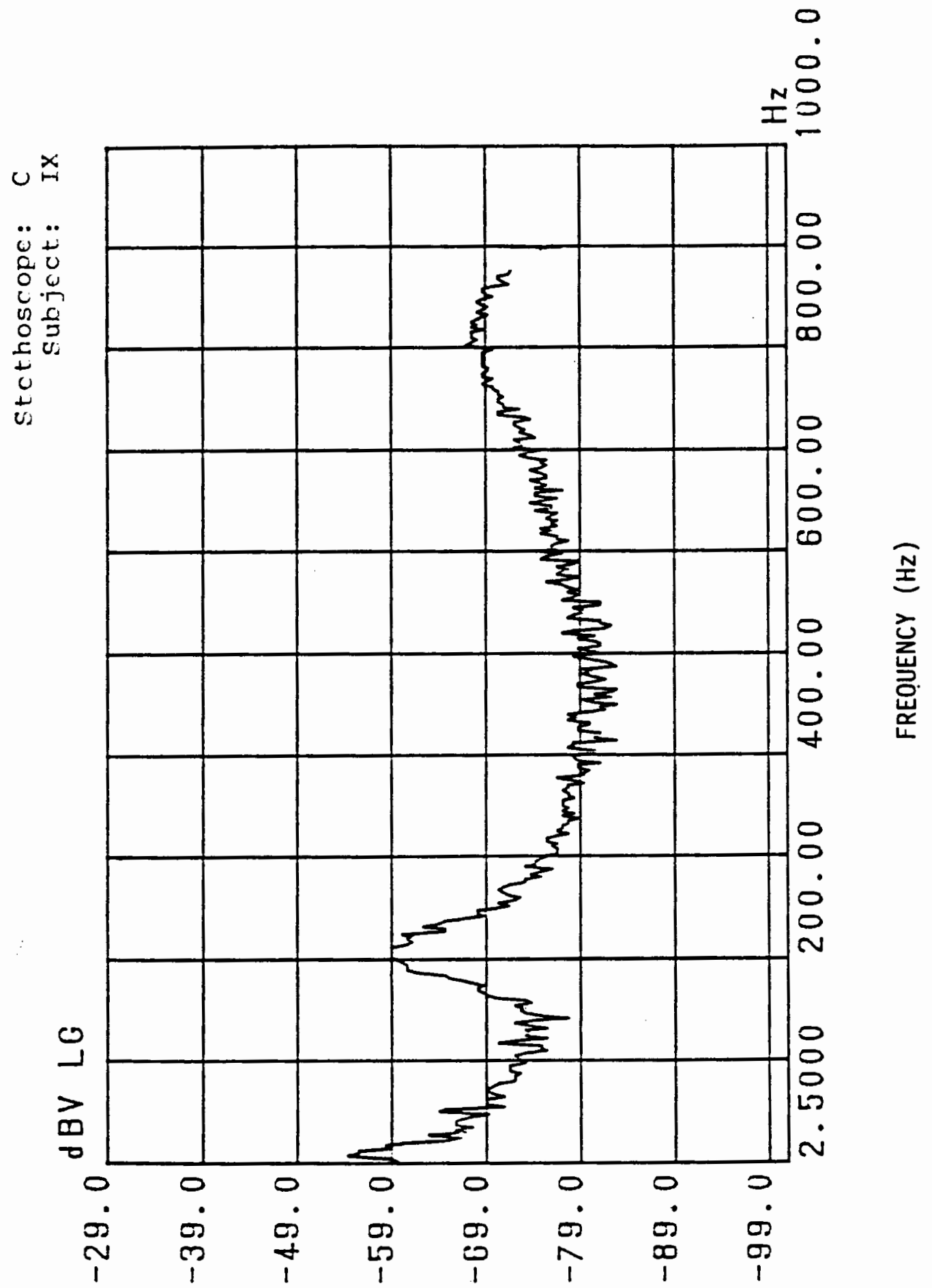

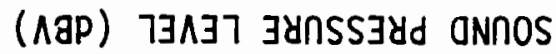




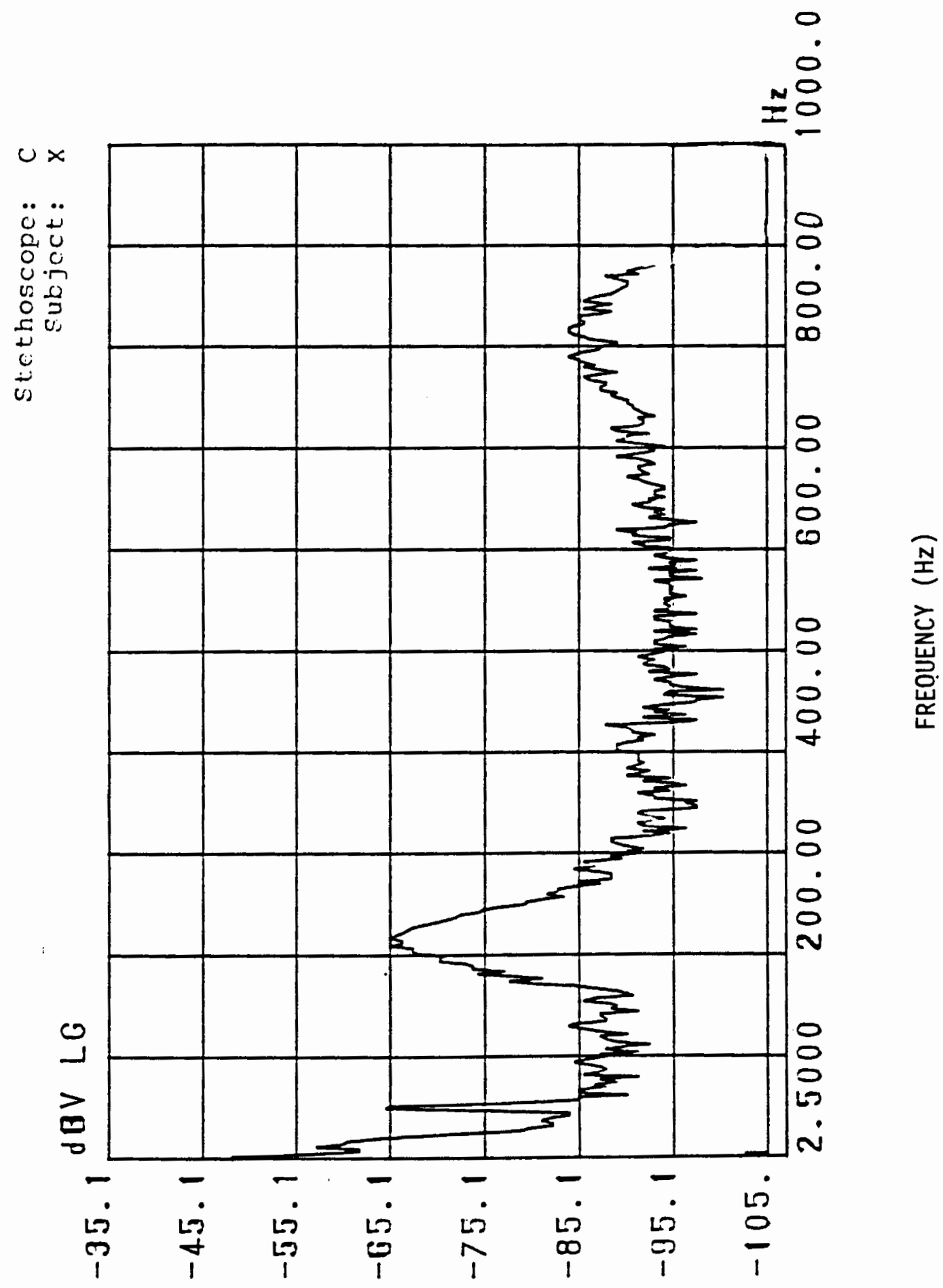

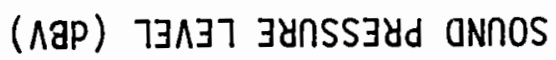




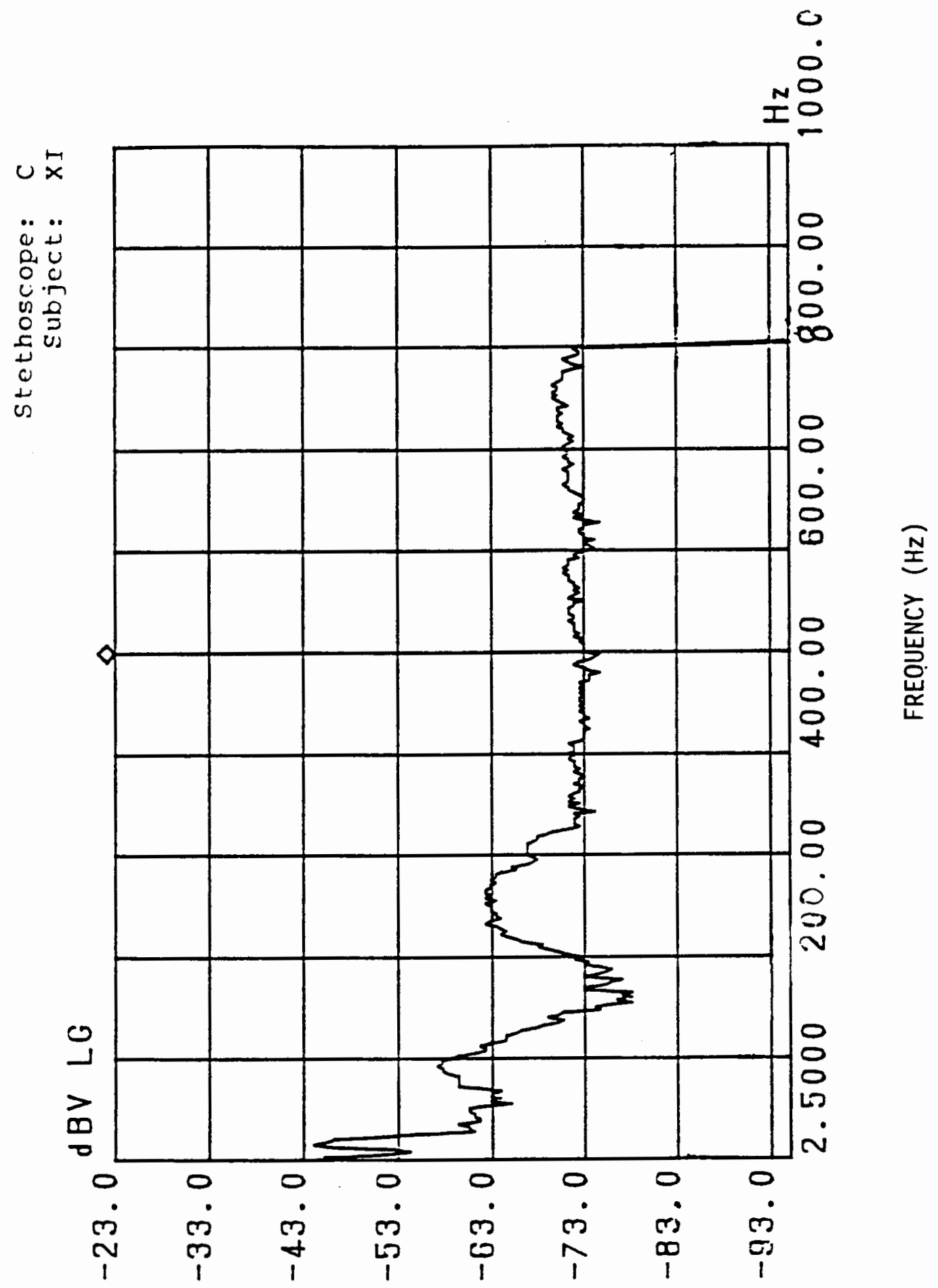

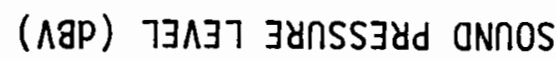

